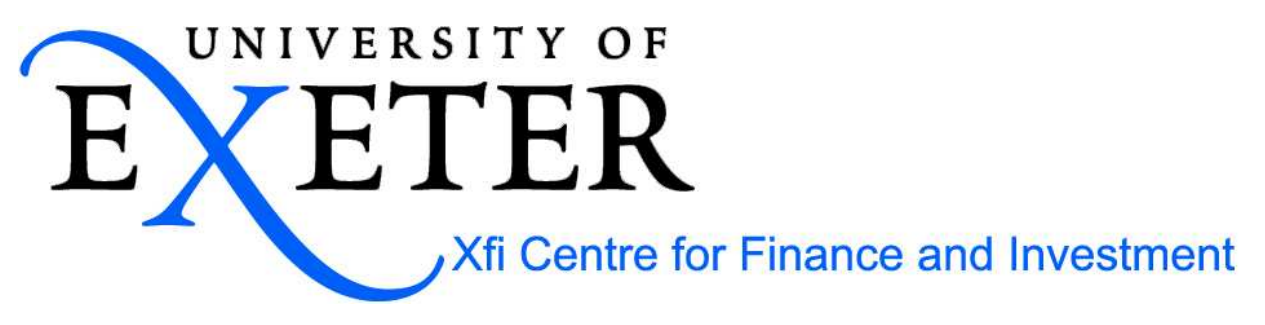

\title{
Performance and Performance Persistence of "Ethical" Unit Trusts in the UK
}

\author{
Alan Gregory* \\ Julie Whittaker**
}

Paper Number: 05/04

November 2005
*Centre for Finance and Investment (Xfi)
**Department of Management

\section{School Of Business and Economics University of Exeter}

First draft. Please do not quote without permission

We would like to thank colleagues and seminar participants at the University of Exeter for their comments on an earlier version of this paper, Richard Harris for his helpful suggestions on test statistics, and Maria Michou for her assistance with updating the Fama French and Momentum factors used in this paper. The usual caveats with respect to errors and omissions apply. 


\title{
Performance and Performance Persistence of "Ethical" Unit Trusts in the UK
}

\begin{abstract}
Using UK style portfolios that are free of any survivorship bias we examine performance, and persistence in the performance, of UK "ethical" or SRI funds, and compare them to a control group of non-SRI funds. In addition, given evidence that many UK funds which claim to be international in nature may exhibit home bias in their portfolio allocations, we propose a new measure for performance of international funds that allows for this and show that such recognition has important implications for the conclusions drawn on performance. We show that SRI funds have less exposure to HML, but greater exposure to SMB and momentum factors, and that neither SRI nor non-SRI funds exhibit significant under performance on a risk/style adjusted basis, despite comparatively poor absolute performance. We also show that performance appears to be time-varying, and that conclusions on performance itself are influenced by whether a static or time varying model is employed. We then examine persistence in fund performance and find evidence that supports persistence. In addition, we find there are differences in performance persistence between ethical and non-ethical funds, but conclusions on the degree of persistence and the direction of persistence appear to depend on the performance metric chosen. However, it is always the case that past winner "ethical" funds outperform "loser" ethical funds at 12 month horizons, such that there is evidence that "ethical" investors can enhance investment performance by investing in past "winners" and avoiding past "losers".
\end{abstract}




\section{Performance and Performance Persistence of "Ethical" Unit Trusts in the UK}

\section{Introduction}

Increasingly market choices are being made that reflect attitudes to social issues. ${ }^{1}$ Within financial markets, investors can give some expression to their social concerns by depositing money in companies that meet certain ethical criteria. Investing in such a manner requires additional information and accordingly a large proportion of socially responsible investment (SRI) is conducted through institutions, charities, churches, pension funds and insurance companies. However, ethical unit trusts, now more commonly referred to as SRI funds, provide a means for individuals to invest sums according to ethical criteria without personally engaging in company research and the market for these funds is growing. Within the UK, for most years during the decade 1989-1999, the value of SRI unit trusts grew at a faster annual rate than the whole unit trust market. In 2003 it was valued at a minimum of $£ 4.2$ billion, an increase of over $25 \%$ since 2000 (EIRIS, 2005).

Although some investors in SRI funds are willing to accept lower returns for their moral stance (Lewis and Mackenzie (2000), Webley, Lewis and Mackenzie (2001)), the performance of SRI funds vis-à-vis non-SRI funds remains of interest. First, growth in the SRI sector will require funds to appeal to a wider group of investors than those with a combination of strong principles and an income level that can support potentially suboptimal returns. Second, the effects of ethical criteria on financial performance have relevance for company strategy. Third, there is intellectual curiosity in considering the performance of funds chosen from a restricted universe of companies. Initially, ethical funds were developed through a negative screening process resulting in the exclusion of stocks of companies engaged in, for example, gambling, tobacco, and human right abuses. Then choice of stocks began to be made on the basis of positive criteria too, such as the inclusion of companies which engage in environmental management. This positive screening permits the inclusion of larger companies which were typically more likely than small companies to be excluded by

\footnotetext{
${ }^{1}$ See for example, Harrison, Newholm and Shaw (2005).
} 
negative screening. Therefore, although still restrictive, the universe for SRI funds has been enlarged.

Previous empirical work on SRI unit trusts in the UK (Luther, Matatko and Corner (1992); Luther and Matatko (1994); Mallin, Saadouni and Briston (1995); Gregory, Matatko and Luther (1997)) have attempted to understand whether performance can be explained by ethical criteria or by other factors such as fund size and composition. With regard to composition of funds the main area of interest has been company size, since larger firms by virtue of their diversity, are more likely to breach ethical criteria. Only Gregory et al. (1997) conducted comparative work using time series and cross series regressions, which also included risk adjusted benchmarks. Their results tentatively suggested that SRI funds did not perform as well as other funds, but that this could be explained by their greater exposure to 'small firms' risk rather than ethical criteria per se. Empirical work on US SRI funds by Hamilton, Jo and Statman (1993) found no significant difference in performance compared with conventional funds. This result was endorsed by cointegration testing by Reyes and Grieb (1998), although they also found that SRI funds did not share a common underlying time trend with other funds. Geczy, Stambaugh and Levin (2003) compared optimal portfolios of funds with SRI objectives and those without, concluding that SRI constraints, is costly when fund managers are skilled. Bauer Koedijk, and Otten (2005), working with US, UK and German data found little significant difference in the performance of SRI and conventional funds, while discerning that older SRI funds performed better than younger ones, indicative of a learning effect.

In this paper, we build on some interesting innovations in Bauer et al (2005). That paper looked at differences in style between ethical and ordinary mutual funds, and also investigated performance of international funds. First, we use UK style portfolios that, by construction, are free of any survivorship bias. Second, we propose a very different measure for performance of international funds that picks up "home bias" in investment allocations. It turns out that the use of such a performance metric changes the finding in Bauer et al (2005) of outperformance by UK funds. Third, we show that performance appears to be time-varying, and that conclusions on performance itself are influenced by whether a static or time varying model is employed. Fourth, as in Blake and Timmerman (1998) and Fletcher and Forbes 
(2002) we examine persistence in fund performance and find results supportive of those in Otten and Bams (2002). However, we find there are differences in performance persistence between ethical and non-ethical funds, and that, as in Fletcher and Forbes (2002) conclusions on the degree of persistence appear to depend on the performance metric chosen. Overall, our findings do not suggest that ethical investors lose out compared to "ordinary" investors, but absolute returns are low and the style exposure of ethical funds looks very different to that of ordinary funds.

\section{Data}

For each year from Jan 89 to Dec 02, we collected returns for all 32 ethical unit trusts that have existed in the UK up until that point, whether alive or dead ${ }^{2}$. At the end of the sample period, dead funds comprised $12.5 \%$ of all funds that had been in existence. For each of these funds, we formed a randomly selected but characteristicmatched portfolio of 5 non-ethical unit trusts. The matching criteria were: 1 . the fund should have a start date within 6 months of the ethical UT with which it is matched, and; 2 . the fund should be in the same AUTIF category. Where (1) could not be met, the start date was relaxed to within 9 months.

The most striking element of summary data is that $29.93 \%$ of our control sample die before the end of the sample period ${ }^{3}$ compared with the relatively low rate of demise for ethical funds. Blake \& Timmerman's (1998) sample (admittedly for a longer period, 72-95) shows a non-survival rate of $41 \%$, so the low failure rate of "ethicals" or SRI funds is remarkable in this context.

Our first tests involve calculating average returns and wealth relatives. Here, our tests are equivalent to forming each month: 1 . an equally weighted "fund of funds" of all UTs available at that date; 2 . a "hedge" portfolio, equivalent to a long position in the ethicals fund of funds and a short position in the non-ethicals fund of funds.

\footnotetext{
${ }^{2}$ Note: Bauer et al (2005), who are also careful to control for survivorship bias in their sample of SRI funds, have an identical number of ethical funds.

${ }^{3}$ Bauer et al (2005) using a slightly shorter period (1990-2000) and different matching criteria report a similar figure, with $28 \%$ of their whole sample disappearing before the end of the measurement period.
} 


\section{Measuring Unit Trust Performance}

One approach is to measure performance using either a single, three factor or four factor model. The standard Fama-French three factor model has factors which are the excess return on the market $R_{m t}-r_{f t}$, the returns on a size factor $S M B_{t}$ (the difference between the returns on a portfolio of small companies and a portfolio of large companies) and a book-to-market factor $H M L_{t}$ which is the difference in returns on a portfolio of high book-to-market companies and low book-to-market companies. The four factor model adds a momentum factor $M O M_{t}$, the difference in returns between a "winner" portfolio and a "loser" portfolio, formed on the basis of the previous 12 months' returns. The 4-factor model $^{4}$ can be described as:

$$
R_{p t}-R_{f t}=\alpha_{p}+\beta_{p}\left(R_{m t}-R_{f t}\right)+\gamma_{1 p} S M B_{t}+\delta_{p} H M L_{t}+\lambda_{\mathrm{p}} M O M+\varepsilon_{\mathrm{pit}}
$$

This model can be estimated for each fund or portfolio $p$ over the full $t$ data periods, when under null hypothesis of no-abnormal performance the $\alpha_{p}$ coefficient should be equal to zero. A potential problem with this approach is that it imparts some lookahead bias if funds are required to survive for a certain minimum number of months in order to be incorporated into the sample. Besides the obvious problem that such a bias presents for any investigation, it could have particularly serious implications for a study using a small number of funds where survivorship differs between the SRI and non-SRI sub-samples.

For that reason, we estimate equation (1) by regressing an equally-weighted portfolio of excess returns on the unit trusts in calendar time. As Blake and Timmermann (1998) point out, this avoids making any assumption about the cross-section relationship of returns between funds. This approach is analogous to that proposed for event tests by Fama (1998) and Mitchell and Stafford (2000). The alternative, which avoids any look ahead bias, is to run equation (1) for individual funds on a rolling basis for months $\mathrm{t}=\mathrm{T}$ to $\mathrm{t}=\mathrm{T}+36$, then use the stored regression coefficients to calculate the abnormal performance for month $\mathrm{T}+37$. This has the advantage of enabling performance to be observed for each fund without incorporating any look

\footnotetext{
${ }^{4} 1$ and 3 factor models amount to special cases of the 4-factor model with the coefficient on MOM (and $S M B$ and $H M L$ in the case of the single factor model) constrained to equal zero.
} 
ahead bias. In these regressions we require the fund to have a minimum of 18 months prior returns in order to estimate the coefficients for month $\mathrm{T}+37$. This rolling regression approach can also be employed for calendar time portfolios. The regressions are run for successive over-lapping 36 month periods starting in January 1989. To test the hypothesis that the Jensen alphas and other coefficients from these rolling regressions are significantly different from zero required a t-statistic that is robust to the overlapping nature of the data. This can be achieved by running a regression of the estimated alphas (or other coefficients) on a constant, with the test statistic being estimated by the Newey-West procedure allowing for the 35 overlapping observations. We also separate our sample into two equal periods (with 66 months in each) and estimate Wald statistics to test for performance differences between first and second halves, once again allowing for overlapping observations using a Newey-West procedure. ${ }^{5}$

Alternative approaches to time-varying performance are either to test directly for market timing skill, or to estimate a conditional model. The Treynor-Mazuy test for market timing includes a quadratic term in the return regression so that successful timing is indicated by a positive coefficient on the squared market return term. A similar logic can be applied to exposure to the other factors.

$$
\begin{aligned}
R_{p t}- & r_{f}=\alpha_{p}+\beta_{p}\left(R_{m t}-r_{f}\right)+\gamma_{p} S M B_{t}+\delta_{p} H M L_{t}+\lambda_{p} M O M_{t}+\eta_{p}\left(R_{m t}-r_{f}\right)^{2}+\phi_{p}\left(S M B_{t}\right)^{2}+ \\
& +\varphi_{p}\left(H M L_{t}\right)^{2}+\kappa_{p}\left(M O M_{t}\right)^{2}+\varepsilon_{p t}
\end{aligned}
$$

Alternatively, Ferson and Schadt (1996) have proposed a conditional performance model, the rationale being that publicly available information has a role in determining future returns, in which case we might expect managers to make use of this to time-vary their market exposure. Under a conditional CAPM, the regression becomes

$$
R_{p t}-R_{f t}=\alpha_{p}+\beta_{0 p}\left(R_{m t}-R_{f t}\right)+\beta_{1 p}^{\prime}\left(z_{t-1}\left[R_{m t}-R_{f t}\right]\right)+\varepsilon_{\mathrm{it}}
$$

\footnotetext{
${ }^{5}$ The authors are grateful to Richard Harris for these suggestions on significance testing.
} 
where $z_{t-1}=Z_{t-1}-E(Z)$ is a vector of deviations of the Zs from their unconditional means. Instruments used are: the lagged treasury bill rate, the lagged dividend yield, the slope of the term structure (difference between long and short run government bond yields), and a dummy variable for January. In addition, we estimate a three and four factor version of this model. These are conceptually different tests from the rolling regression tests described previously. Under the conditional model, time varying exposures occur in response to publicly available information. The market timing model is silent on whether changes in risk exposure are in response to publicly available information, but measures the success of timing through the factor return squared terms. By contrast, the rolling regressions simply allow factor exposures to change through time, with no priors on what these changes may or may not be in response to.

The above are perfectly reasonable models for estimating domestic fund performance, but 12 out of our 32 ethical funds are "international". One alternative is to simply run the above regressions using a suitable world index. However, inspection of the investment strategies of these funds shows evidence of home bias and considerable variation in the degree of this bias between the funds. This home bias can be measured by extending the four factor model in (1) to incorporate home bias not only in the exposure to the domestic market, but also in the domestic, $S M B, H M L$ and $M O M$ factors. We investigate various proxies for the world factors, with the most successful appearing to be the use of the MSCI World index and the US factors from Kenneth French's web page, translated into sterling returns. We then measure home bias for each factor as (HOMEFACTOR - WORLDFACTOR), which we describe as $(R w-R m), S M B d, H M L d$ and $M O M d$ respectively, giving the following model:

$$
\begin{aligned}
& R_{p t}-R_{f t}=\alpha_{p}+\beta w_{p}\left(R_{w t}-R_{f t}\right)+\gamma w_{1 p} S M B w_{t}+\delta w_{p} H M L w_{t}+\lambda w_{\mathrm{p}} M O M w+ \\
& \beta w_{p}\left(R_{w t}-R_{m t}\right)+\gamma h_{1 p} S M B d+\delta h_{p} H M L d_{t}+\lambda h_{\mathrm{p}} M O M d+\varepsilon_{\mathrm{pit}}
\end{aligned}
$$

In addition to testing for evidence of fund out-performance, we also examine the consistency or persistence of fund performance. Given the small number of SRI funds here we use the contingency table tests common in the literature (for a UK case applied to unit trusts, see Fletcher and Forbes, 2002). We classify funds as winners or 
losers in each of two consecutive time periods (which can be 1 month, 3 month, 6 month or 12 months), and then count the number of successive periods' winners or losers, resulting in a four way classification based upon two-period performance, namely: winner-winner (WW), winner-loser (WL), loser-winner (LW), and loserloser (LL). We compute the number of combinations and the following related statistics (see Carpenter and Lynch, 1999): the percentage of repeat winners, PRW = $\mathrm{WW} /(\mathrm{N} / 2)$, with a Chi-Squared test with 1 d.o.f. where $\mathrm{CHI}=\left\{(\mathrm{WW}-\mathrm{N} / 4)^{2}+(\mathrm{WL}-\right.$ $\left.\mathrm{N} / 4)^{2}+(\mathrm{LW}-\mathrm{N} / 4)^{2}(\mathrm{LL}-\mathrm{N} / 4)^{2}\right\} / \mathrm{N} / 4$ (we also compute these figures for the difference between SRI and non-SRI funds $)$; and the cross-product ratio $\mathrm{CP}=(\mathrm{WW} \times$ $\mathrm{LL}) /(\mathrm{WL} \times \mathrm{LW})$ which we test using the log-odds ratio of Brown and Goetzman (1995) and Fletcher and Forbes (2002).

We do not use decile portfolios (as in Otten and Bams, 2002) here because of the low number of ethical funds. Instead, we perform two types of test, in keeping with Fletcher and Forbes (2002). First, for all funds, segregated into domestic and international, we form winner-loser portfolios and report results on that basis. Second, for the domestic group, as in Blake and Timmerman (1998) we form quartile (rather than decile) portfolios, and report results on that basis. Given the small number of international ethical funds, we do not undertake this latter analysis for those groups. We define "winners" and "losers" by the following means: Jensen alphas from the 3 factor and 4 factors models, and; absolute returns. Note that in all cases we define cut-offs across the whole sample, not separately for SRI and non-SRI groups.

\section{Results}

Our first results (Table 1) record results based upon the absolute performance of the funds on a calendar time portfolio (with equal weightings) basis. These record a disappointing level of performance for all funds relative to market benchmarks. For domestic funds, the ethical (SRI) funds under-perform non-SRI funds by $0.56 \%$ p.a., but have lower absolute risk (13.8\% standard deviation versus $15.6 \%$ for the non-SRI funds). The wealth-relative figures show the cumulated value of the calendar funds at the end of December 2002. The performance of the international funds are particularly disappointing, and here the SRI funds under-perform the control group of 
non-SRI funds by around 1\% p.a.. Furthermore, the risk of these funds is marginally higher than that of the control group (14.95\% standard deviation versus $14.68 \%$ ).

In Table 2 we report results from a basic Jensen alpha model run in calendar time. We report these for single, three and four factor models. We also report results for "hedge" portfolios which are long in SRI funds and short in non-SRI funds. Turning to the domestic funds, the first message from the results is that none of the alphas are significant under any model. As might be expected from the absolute results reported in Table 1, performance is marginally negative for both SRI and control group funds, but never significantly so. Furthermore, there are no differences in the alphas between the two groups of funds under any of the models. Our results are not qualitatively different from those of Bauer et al, although our alphas are considerably closer to zero. This reflects differences in our market indices (FTASI versus Worldscope) and factor construction, which, in contrast to those based upon Worldscope figures, are based on Datastream figures including those from the dead companies file, which should avoid any survivorship bias being present in our factors. We find that there are significant differences in style/factor exposures. First, SRI funds have lower market exposures. Betas are close to unity for the control group, but significantly less than unity for the SRI funds. The difference in betas is highly significant under all three models. Second, the size-exposure is significantly positive for both groups, but the SRI funds have significantly greater exposure to this factor. The SRI funds have an insignificant negative exposure to the HML factor, whereas the non-SRI group have a significant positive exposure; the difference between the groups is significantly negative. Last, whilst neither group of funds has significant exposure to the momentum factor, we find that SRI funds have a significantly greater exposure to the factor. Although our findings in respect of differences in market risk, $S M B$ and $H M L$ factor loadings are similar to those of Bauer et al, there are differences in a number of respects. First, the factor loadings on $S M B, H M L$ and $M O M$ are different in magnitude and tend to be less significant for both groups. Second, our finding on differences in momentum exposure contrast to theirs.

For the international funds, our approach reveals significant home bias in exposures to market and SMB factors for SRI and non-SRI funds, although the significance level is slightly over $5 \%$ for the latter. Both groups also have significant exposure to 
international market and SMB factors. However, there is no significant exposure to HML, either domestically or internationally, for either group. Extending the analysis to a four factor model adds nothing, and exposure to the momentum factor (home bias and international) is always insignificant. We also show negative but insignificant alphas of around $0.1 \%$ per month for both SRI and non-SRI funds. The only significant factors on the hedge fund are that both international SMB exposure and home bias in SMB exposure are positive, which is in line with the finding from the domestic analysis which illustrated that "ethical" funds have greater exposure to size effects. Our results stand in some contrast to Bauer et al, (Table 5, p.1761) who report insignificant positive alphas, significant HML and momentum exposures, and significant differences on all factor exposures between SRI and non-SRI groups.

In Table 3, we investigate timing effects using the Treynor-Mazuy approach and a Ferson-Schadt style conditional model. Two general observations are in order before discussing the detail of the analysis. The first is that whilst potentially interesting findings arise with result to timing ability, in no case does an analysis based on either of these approaches change our general conclusions with regard to factor exposures and performance. The second is that in no cases are any of the time varying coefficients significant for the international funds. For that reason, we do not report the timing effect regressions for these funds. ${ }^{6}$ Turning to the Treynor-Mazuy regressions, the market timing coefficient $(R m-R f)^{2}$ is significantly negative for both SRI and non-SRI funds using any of our factor models. Except in the case of the CAPM, where the negative difference is significant at the $10 \%$ level, there are no significant differences between SRI and non-SRI funds. There is no evidence of any timing ability with respect to the SMB factor, and neither is there any significant difference between funds in their ability to time exposure to SMB. Intriguingly, however, both SRI and non-SRI funds appear to have the ability to time exposure to the HML factor and furthermore analysis of the hedge portfolio reveals that SRI funds have significantly superior ability to time this exposure. At the same time, SRI funds have negative ability to time WML exposure, although they are not significantly worse than the non-SRI group in this regard.

\footnotetext{
${ }^{6}$ Results are available from the authors on request.
} 
The alternative approach to time varying returns, using the conditional asset pricing models, adds little to the analysis except to reveal that non-SRI funds exhibit a negative loading on the $J A N(R m-R f)$ variable, suggesting that they under-perform in the month of January, though in this regard they are not significantly worse than the SRI funds.

An alternative approach is to investigate time-varying performance by estimating regressions on a rolling basis. Of course, a sub-period analysis could be used (as in Bauer et al) but running rolling regressions allows for continual variation in factor exposure and performance. A further advantage is that next month's abnormal performance can always be estimated for individual funds (as well as calendar portfolios) based upon the current estimates of their factor exposures. The results in Table 4 show factor exposures for the calendar time portfolios based upon these rolling 36 month regression, along with the Newey-West test p-values described above. These results reveal important differences from those reported in Tables 2 and 3 above. Perhaps the most important is that although rolling regressions confirm that neither SRI nor non-SRI funds exhibit significant out-performance, the results reveal that Domestic SRIs have significantly better performance than non-SRI funds using either the 3-factor or 4-factor models. Consistent with the findings of Bauer et al, the Wald test result shows that this significantly superior performance arises in the second period rather than the first. The "hedge change, second period" alpha is roughly $0.2 \%$ per month better than the first period alpha, whichever model is used. This change in performance shows up clearly in Figures 1 (3-factor) and 2 (4-factor) which charts the alpha coefficients for SRI, non-SRI and hedge portfolios through time. Turning to the factor exposures, the qualitative results for market and SMB exposures are unchanged, but non-SRI funds have a significant exposure to HML at only the $10 \%$ level under the 3-factor model, and exposure to the momentum factor of SRI funds is significantly positive at the $10 \%$ level. All conclusions on differences in factor exposures (i.e. the hedge fund exposures) are unchanged under the rolling regressions. However, the Wald tests show that there are significant changes in the hedge fund exposure to market risk and WML between first and second periods. ${ }^{7}$ This suggests that relative to non-SRI funds, SRI funds appear to significantly increase their

\footnotetext{
${ }^{7}$ Changes in respect of the SMB factor are only significant under the 3-factor model.
} 
exposure to market risk and momentum in the second period. The hedge fund coefficients are shown in Figures 4 (3-factor) and 5 (4-factor).

Within the International funds, again important differences arise compared with those reported in Table 2. First, non-SRI funds now significantly under-perform, by around a quarter of one percent a month, although the hedge results reveal no significant difference in performance (see also Fig. 3). Second, on a time varying basis both SRI and non-SRI portfolios have significant positive exposure to international HML. Third, SRI funds exhibit significantly less exposure to home HML but more exposure to international HML. Last, our Wald tests reveal significant changes in exposure to the world market and size factors through time. The plot of the factor exposures is illustrated in Figure 6. Taken as a whole, our results in Table 4 suggest that it is important to allow for changes in style/factor exposure in performance measurement tests. These changes can come about either because individual funds change their portfolios, or because the mix of funds within the portfolio changes.

In Table 5 we report average monthly abnormal performance figures for individual funds calculated by running rolling regressions. Like the calendar time portfolios these are free of survivorship bias in that they represent an implementable investment strategy, though unlike the calendar time funds the approach requires a fund to have been in existence for at least 18 months before its factor exposure can be calculated. Hence the Table 5 results are the average performance figures for funds which have met a pre-survival criterion. The results present a simple pooled average for each model, together with simple T-tests and a T-test for differences (assuming unequal variances). These results tend to contradict those of Table 2, but are not inconsistent with those of Table 4. There are, however, differences between Table 4 and Table 5 in terms of statistical significance. Turning to the three factor model, the Table 5 results show a significant positive abnormal performance for SRI funds of around $0.2 \%$ per month, compared with an (insignificant) alpha value equivalent to about $0.1 \%$ per month in Table 4 . The non-SRI mean is an insignificant but positive $0.06 \%$ per month, compared with an insignificant negative alpha. However, the difference in performance between funds is similar ( $0.14 \%$ per month), although in contrast to the Table 4 results the difference is not significant here. The 4-factor performance figure for both sets of funds in Table 5 is positive but not significantly different from zero. 
The difference in performance is somewhat smaller than indicated by Table 4, and is statistically insignificant. However, consistent with Table 4, none of the performance figures for international funds are significantly different from zero, and neither is the difference in performance significant. The international multi-factor model reveals positive performance which is not significantly different from zero for either group of funds, and although SRIs out-perform the non-SRIs, the difference is not significantly different from zero.

Overall, the results from Tables 1-5 can be summarised as follows. Whilst the absolute performance of both sets of funds is disappointing, there is no evidence of any significant difference in performance, and little evidence of significant over or under performance on a risk-adjusted basis, however performance is measured. There are clear risk differences between SRI and non-SRI funds, however. Furthermore there is evidence of time variation in performance and risk exposures, coupled with at least some evidence that suggests allowing for this time variation is capable of changing conclusions.

We now proceed to consider persistence in performance. Given the evidence summarised above, we use the rolling performance and risk exposure data in these tests from both the 3 and 4 factor model analyses. In addition, we look at what conclusions may be drawn if we use absolute performance to rank performance. As explained above, we start with simple winner-loser portfolios, and these are presented in Tables 6 to 10 inclusive. We measure four short-term performance horizons: one month; three months; 6 months; and 12 months. We also show overall persistence (the SRI plus non-SRI funds) and persistence for SRI and non-SRI funds separately. Two tests are presented: a chi-squared test for differences between the distribution of repeat winners and repeat losers, together with the percentage of repeat winners $(\mathrm{PRW})$, and the cross-product ratio $(\mathrm{CP}=(\mathrm{WW} \times \mathrm{LL}) /(\mathrm{WL} \times \mathrm{LW}))$ together with a $\mathrm{Z}$ test on the CP ratio. We also report whether PRW is significantly greater or lower between SRI and non-SRI funds.

In Table 6 we present results for domestic funds using absolute returns to rank firms and measure subsequent performance. Overall, we see significant persistence as measured by the chi-squared test at intervals of 6 and 12 months, though no 
significance is observed using the CP test. The SRI group exhibit significantly lower repeat winners than would be expected under the null hypothesis ${ }^{8}$ for both 6 and 12 month horizons, though no significance is observed under the Z-test. Inspection of the full matrix of results ${ }^{9}$ shows that this is because there are a high number of repeat losers coupled with a low number of repeat winners. The $\mathrm{CP}$ ratio will tend to become significant when there is persistence in both winners and losers. By contrast, there is a significant percentage of repeat winners amongst the non-SRI control funds for periods of 3, 6 and 12 months. Furthermore, non-SRI funds show significantly more repeat winners than SRI funds for all performance measurement intervals. Intriguingly, these conclusions do not hold when persistence is examined under either the three or four factor models. When we examine performance on a three-factor basis in Table 7, we see that overall there is some evidence of modest persistence at 1 , 6 and 12 month horizons, although this again shows through in the difference in percentage in repeat winners rather than through the $\mathrm{CP}$ ratio. At the 1 month horizon both SRI and non-SRI funds exhibit a PRW ratio significantly less than $50 \%$, with no significant difference between the groups. At the 3 month horizon, SRI funds have a PRW ratio significantly greater than $50 \%$, though this significance does not hold for longer periods. The non-SRI funds have significantly less than 50\% PRW for 3 and 6 though significantly greater than $50 \%$ for 12 month horizons. However for all horizons of 6 months and beyond they exhibit significantly less persistence than their SRI counterparts.

When performance is measured on a 4-factor model the result is rather different. As with the Fletcher and Forbes result, our conclusions on performance persistence alter when a 4-factor model is used, but in the opposite direction to their findings. Here, we find greater evidence of persistence when we switch to a 4-factor model. Given the clear evidence on time variation in performance and factor loadings, together with differences between factor returns between the first and second halves of our study period, we believe the most likely explanation for the difference in results is simple calendar time variation in fund behaviour (note that the Fletcher and Forbes analysis covers 1983-1996 in contrast to our 1989-2002 period), . For our overall sample we find negative persistence at short horizons ( 1 and 3 months), but positive persistence

\footnotetext{
${ }^{8}$ The expectation would, of course, be $50 \%$ under the null.

${ }^{9}$ Not reported for reasons of space, but available from the authors on request.
} 
at the 12 month horizon. Furthermore, at this horizon the $\mathrm{CP}$ ratio is significant at the $10 \%$ level. For the SRI funds, we observe negative performance persistence at the 3 month horizon, though no other horizons are significant. For non-SRI funds we observe negative persistence at the 1 month horizon, with strong positive persistence at the 12 month horizon. At 1 and 12 month horizons there is more persistence in non-SRI funds, but at 3 and 6 month horizons SRI funds show more persistence. Whilst some of these patterns are curious, it seems clear that switching from a three to a four factor model has a significant impact both on the PRW statistic and also on the differences in persistence between SRI and non SRI funds.

Persistence tests for the International funds are reported in Tables 9 and 10. Table 9 shows the results based on absolute performance. Results for the overall sample indicate that only at a 12 month horizon is significant persistence observed, and then only on the basis of a PRW test. For the SRI sample, the PRW is less than 50\% at the 1 month horizon (with a chi squared test significant at the $10 \%$ level), greater than $50 \%$ at the 3 month horizon (again with a chi squared test significant at the $10 \%$ level), with a significant PRW less than $50 \%$ at the 12 month horizon. Whilst persistence is not significant at the 5\% level for 1-6 month horizons, though significant at the $10 \%$ level with a PRW of $64.8 \%$ at the 12 month horizon, as with their domestic counter-parts the international non-SRIs always exhibit significantly greater persistence and higher PRWs than the SRI funds. On a multi-factor basis (Table 10) overall significant persistence is observed at 1, 3 and 12 month horizons (at least at the 10\% level) with PRWs being less than 50\% for shorter periods, but greater than $50 \%$ for the 12 month horizon. SRI funds exhibit marginally significant persistence at 3 and 6 month horizons, but the significant persistence at the 12 month horizon is associated with a PRW of less than 50\%. For the non-SRI funds there is a low PRW for 1 and 3 month horizons, with a significant with a chi squared test (at the $10 \%$ level), but no evidence of significant persistence beyond that point. However, at the 6 month horizon non-SRI funds exhibit marginally greater persistence than SRIs, and significantly greater positive persistence at the 12 month horizon, though at the 3 month horizon SRI funds exhibit marginally greater significance. Finally, note that taken as a whole, our findings on persistence at the 12 month horizon are compatible with those in Tonks (2002) and Gregory and Tonks (2005) 
Our final tests for persistence involve partitioning funds into quartiles based on their prior 12 months' performance. We carry out tests using absolute, 3-factor abnormal returns, and 4-factor abnormal returns as the ranking measure. Funds are put into portfolios according to prior performance, and these returns regressed on factors for the following 12 months. As with the winner-loser tests we use overall sample cutoffs to determine portfolio membership. We are not able to do this test for the international funds because there are simply too few funds to form meaningful quartile portfolios. In Table 11 we report results for the 3 -factor model. The rows of the Table report regression results for the quartiles 1 (best prior performance) to 4 (worst prior performance), whilst the columns show results for the overall sample, and the SRI and non-SRI sub-samples. The last rows in the table report results for the "winner" (Q1) minus the "loser" (Q4) portfolio. Note that in contrast to Table 7, these results are for portfolios of funds formed in calendar time and then regressed on factors and, of course, partitioning is by quartile rather than median performance. For the overall results note that only the bottom quartile of funds have significantly persistent performance (at the 10\% level), which is negative. The winner-loser portfolio exhibits significant positive persistence, and intriguingly a highly significant negative exposure to HML. For the SRI group, a more significant negative persistence is observed for Q4, with a similar result to the overall sample being seen for the winner-loser portfolio. However, for the non-SRI group whilst the Q4 performance is significantly negative (at the $10 \%$ level), the performance of the winner-loser portfolio is not significantly different from zero, although the SMB loading is significantly positive and the HML loading is significantly negative.

Table 12 reports these results based upon a four-factor model. Overall, only the Q3 portfolio exhibits performance persistence, which is negative. Intriguingly, whilst the hedge portfolio now exhibits weakly positive persistence, not only is the HML loading significantly negative but the SMB and momentum loadings are significantly positive. For the SRI sub-sample, both Q3 and Q4 exhibit significantly negative performance. The hedge portfolio has significant positive performance and a significantly negative HML loading. However, none of the non-SRI portfolios show significant performance, and neither is there any significant difference in performance. 
Last, in Table 13, we report results where prior absolute performance determines quartile membership. As a result, we use three benchmarks for post-formation performance: a 1-factor model; a 3-factor model; and a 4-factor model. Turning to the overall portfolio first, we observe no persistence in performance when a single factor model is employed, although the "hedge" portfolio does exhibit significant performance at the $10 \%$ level. When we switch to a 3 -factor model we observe negative persistence (significant at the 10\% level) in the Q4 portfolio, and a significant negative persistence for the hedge portfolio. This persistence is maintained when we move to a 4-factor model. For the SRI funds there is no persistence under the single factor model, although the hedge portfolio has significant persistence at the $10 \%$ level. Under the 3 -factor model none of the quartile portfolios exhibit significant persistence but again the hedge portfolio has significantly positive performance and a significantly negative HML exposure. A similar story applies under a 4-factor model, although under this model we see a significant positive exposure to the momentum effect in the W-L portfolio. Non-SRI funds exhibit no significant persistence under any model, and neither does the hedge portfolio exhibit any persistence. The major message from these regressions is that "ethical" investors may be well advised to avoid funds that have exhibited poor performance over the previous 12 months in favour of those which have exhibited superior performance.

One possible factor in explaining our findings on persistence may be the "UK smaller companies" persistence result for Blake and Timmerman (1998). On a risk-adjusted basis, they find a difference between top and bottom quartile performers in excess of $0.5 \%$ per month for this group, as opposed to around $0.1 \%$ for the UK general group of funds. As we report above, SRI funds are significantly more exposed to the SMB factor than the control group, which may play an important role in explaining the difference in persistence between the two groups.

\section{Conclusions}

Using UK style portfolios that are free of any survivorship bias we have examined performance and persistence in performance of UK "ethical" or SRI funds, and compared them to a control group of non-SRI funds. In addition, given the evidence that many UK funds which claim to be international in nature may exhibit home bias in their portfolio allocations, we have proposed a measure for performance of 
international funds that picks up this "home bias", and we further show that such recognition has important implications for conclusion drawn on performance. These initial tests show that SRI funds have less exposure to HML, but greater exposure to SMB and momentum factors. However, neither SRI nor non-SRI funds exhibit significant under performance on a risk/style adjusted basis, despite comparatively poor absolute performance. In addition, we show that performance appears to be time-varying, and that conclusions on performance itself are influenced by whether a static or time varying model is employed. That said, we do not show unambiguously significant positive out-performance, but we do show that on a time varying basis, net of risk/style effects, domestic SRI funds may out-perform their control group of nonSRI funds, although this is only true for calendar time portfolios. Last, we have examined persistence in fund performance and find evidence that supports persistence. In addition, we find there are differences in performance persistence between ethical and non-ethical funds, but, as in Fletcher and Forbes (2002) conclusions on the degree of persistence and the direction of persistence appear to depend on the performance metric chosen. However, it is unambiguously the case that past winner "ethical" funds outperform "loser" ethical funds at 12 month horizons. In conclusion, although absolute returns are low and the style exposure of ethical funds, particularly domestic funds, looks very different to that of ordinary funds our findings do not suggest that ethical investors lose out compared to "ordinary" investors. However, there is evidence that "ethical" investors can enhance investment performance by investing in past "winners" and avoiding past "losers" however risk and style effects are controlled for.

\section{References}

Bauer R., Koedijk K., Otten R. (2005), 'International evidence on ethical mutual fund performance and investment style', Journal of Banking and Finance, Vol. 29, pp 7511767.

Blake, D. and A. Timmermann, (1998), 'Mutual Fund Performance: Evidence from the UK', European Finance Review, Vol. 2, pp 57-77.

Brown, S. and W. Goetzmann (1995), 'Performance Persistence', Journal of Finance, Vol. 50, pp 679-98. 
Carhart, M. (1997), 'On Persistence in Mutual Fund Performance', Journal of Finance, Vol. 52, pp 57-82.

Carpenter, J.N., and A.W. Lynch (1999), 'Survivorship Bias and Attrition Effects in Measures of Performance Persistence', Journal of Financial Economics, Vol. 54, pp 337-374.

EIRIS (2005), 'Market Statistics' [Internet], Available from:

$<$ http://www.eiris.org/Pages/MediaInfo/MarSta.htm > [Accessed 18 June 2005].

Fletcher, J. and D. Forbes (2002), 'An Exploration of the Persistence of UK Unit Trust Performance', Journal of Empirical Finance, Vol. 9, No. 5, pp 475-496.

Geczy, C., Stambaugh, R. and Levin, D. (2003), 'Investing in Socially Responsible Mutual Funds', Working Paper, University of Pennsylvania.

Gregory A., Matatko J. and Luther R. (1997), 'Ethical Unit Trust Financial Performance: Company Effects and Fund Size Effect', Journal of Business Finance and Accounting, Vol. 24, No.5, pp 705-725.

Gregory, A., and Tonks, I. (2005), 'Performance of Personal Pension Schemes in the UK', Xfi Working Paper, University of Exeter.

Hamilton S., Jo H. and Statman M. (1993), 'Doing Well While Doing Good? The Investment Performance of Socially Responsible Mutual Funds', Financial Analysts Journal, Nov/Dec.

Harrison, R., Newholm, T. and Shaw, D. (2005), The Ethical Consumer, London: Sage Publications.

Lewis, A. and Mackenzie, C. (2000), 'Morals, money, ethical investing and economic psychology', Human Relations, Vol. 53, No. 2, pp 179-191.

Luther R., Matatko J. and Corner D. (1992), 'The Investment Performance of UK Ethical Unit Trust', Accounting Auditing \& Accountability Journal, Vol.5, No. 4, pp $57-70$

Luther R. and Matatko J. (1994), 'The Performance of Ethical Unit Trusts: Choosing an Appropriate Benchmark', British Accounting Review, Vol.26, pp 57-70.

Mallin C. A., Saadouni B. and Briston R.J. (1995), 'The Financial Performance of Ethical Investment Funds', Journal of Business Finance and Accounting, Vol. 22 No.4, pp 483-96.

Mitchell, M.L., and Stafford, E. (2000), 'Managerial Decisions and Long Term Stock Price Performance', Journal of Business, 73 (3), pp. 287-329.

Otten and Bams (2002), 'European Mutual Fund Performance', European Financial Management Vol. 8 No.1, pp. 75-101. 
Reyes, M.G. and Grieb, T. (1998), 'The external performance of socially-responsible mutual funds', American Business Review, January, pp 1-6.

Tonks, I. (2002), 'Performance Persistence of Pension Fund Managers', FMG/UBS Discussion Paper, No. 1, March.

Webley, P., Lewis, A. and Mackenzie, C. (2001), 'Commitment among ethical investors: An experimental approach', Journal of Economic Psychology, Vol. 22, pp $27-42$. 
Table 1: Basic stats:

Absolute performance:

Domestic

\begin{tabular}{||l|r|r|r|r||}
\hline AVERAGES: & MONTHLY & ANNUALISED & FINAL WEALTH & ANNUALISED SD \\
\hline SRI & $0.62 \%$ & $7.75 \%$ & 2.487053382 & $13.76 \%$ \\
\hline Non- SRI & $0.67 \%$ & $8.35 \%$ & 2.591774833 & $15.59 \%$ \\
\hline Rm (FTASI) & $0.83 \%$ & $10.48 \%$ & & \\
\hline Difference & $-0.05 \%$ & $-0.56 \%$ & & \\
\hline Rf & $0.59 \%$ & $7.26 \%$ & & \\
\hline
\end{tabular}

International:

\begin{tabular}{|l|r|r|r|r||}
\hline AVERAGES: & MONTHLY & ANNUALISED & FINAL WEALTH & ANNUALISED SD \\
\hline SRI & $0.54 \%$ & $6.64 \%$ & 2.102313177 & $14.95 \%$ \\
\hline Non- SRI & $0.62 \%$ & $7.72 \%$ & 2.434036369 & $14.68 \%$ \\
\hline Rm (MSCI World) & $1.22 \%$ & $15.65 \%$ & & \\
\hline Difference & $-0.08 \%$ & $-1.01 \%$ & & \\
\hline Rf & $0.59 \%$ & $7.26 \%$ & & \\
\hline \hline
\end{tabular}


Table 2: Basic Jensen model coefficients

\begin{tabular}{|c|c|c|c|c|c|c|}
\hline $\begin{array}{l}\text { DOMESTIC, BASIC JENSEN } \\
\text { ALPHAS }\end{array}$ & SRI & & Non SRI & & Hedge & \\
\hline 1 -factor & Coefficient & T-test & Coefficient & T-test & Coefficient & T-test \\
\hline $\mathrm{Rm}-\mathrm{Rf}$ & \begin{tabular}{|l|}
0.794 \\
\end{tabular} & 24.42 & 0.974 & 42.58 & -0.180 & -7.07 \\
\hline CONSTANT & -0.002 & -1.10 & -0.002 & -1.55 & 0.000 & -0.02 \\
\hline Adj R2 & 0.781 & & 0.916 & & 0.227 & \\
\hline 3-factor & Coefficient & T-test & Coefficient & T-test & Coefficient & T-test \\
\hline $\mathrm{Rm}-\mathrm{Rf}$ & 0.805 & 28.37 & 0.974 & 46.67 & -0.169 & -7.10 \\
\hline SMB & 0.246 & 6.70 & 0.164 & 6.08 & 0.082 & 2.65 \\
\hline $\mathrm{HML}$ & -0.039 & -1.16 & 0.059 & 2.36 & -0.098 & -3.44 \\
\hline CONSTANT & -0.001 & -0.45 & -0.001 & -1.25 & 0.001 & 0.56 \\
\hline Adj R2 & 0.835 & & 0.930 & & 0.328 & \\
\hline 4-factor & Coefficient & T-test & Coefficient & T-test & Coefficient & T-test \\
\hline $\mathrm{Rm}$ - Rf & 0.816 & 27.64 & 0.970 & 44.47 & -0.154 & -6.27 \\
\hline SMB & 0.258 & 6.84 & 0.160 & 5.73 & 0.098 & 3.12 \\
\hline $\mathrm{HML}$ & -0.025 & -0.70 & 0.054 & 2.06 & -0.078 & -2.66 \\
\hline MOM & 0.059 & 1.34 & -0.020 & -0.60 & 0.079 & 2.15 \\
\hline CONSTANT & -0.001 & \begin{tabular}{|r|} 
\\
-0.64 \\
\end{tabular} & -0.001 & -1.16 & 0.000 & 0.26 \\
\hline Adj R2 & 0.836 & & 0.930 & & 0.342 & \\
\hline
\end{tabular}

\begin{tabular}{|c|c|c|c|c|c|c|}
\hline $\begin{array}{l}\text { INTERNATIONAL, BASIC } \\
\text { JENSEN ALPHAS }\end{array}$ & SRI & & NON SRI & & HEDGE & \\
\hline 3-factor, multi & Coefficient & T-test & Coefficient & T-test & Coefficient & T-test \\
\hline HOME (=Rm-Rw) & $\begin{array}{l}0.498 \\
\end{array}$ & 11.29 & \begin{tabular}{|l}
0.446 \\
\end{tabular} & 11.94 & 0.052 & 1.18 \\
\hline Rw-Rf & 0.858 & 33.11 & 0.900 & 41.02 & -0.041 & -1.58 \\
\hline HOMESMB (=SMB-SMBw) & 0.196 & 5.68 & 0.057 & 1.94 & 0.139 & 4.01 \\
\hline SMBw & 0.464 & 11.10 & 0.214 & 6.05 & 0.250 & 5.95 \\
\hline HOMEHML (=HML-HMLw) & -0.004 & -0.12 & 0.021 & 0.79 & -0.025 & -0.78 \\
\hline HMLw & -0.046 & -1.23 & 0.008 & 0.27 & -0.054 & -1.45 \\
\hline CONSTANT & -0.001 & -1.24 & -0.001 & -1.02 & 0.000 & -0.37 \\
\hline Adj R2 & 0.891 & & 0.919 & & 0.203 & \\
\hline 4-factor, multi & Coefficient & T-test & Coefficient & T-test & Coefficient & T-test \\
\hline $\operatorname{HOME}(=\mathrm{Rm}-\mathrm{Rw})$ & 0.501 & 11.27 & 0.448 & 11.93 & 0.053 & 1.18 \\
\hline $\mathrm{Rw}-\mathrm{Rf}$ & 0.865 & 29.88 & 0.906 & 37.01 & -0.041 & -1.40 \\
\hline HOMESMB (=SMB-SMBw) & 0.204 & 5.59 & 0.064 & 2.07 & 0.140 & 3.81 \\
\hline SMBw & 0.467 & 11.01 & 0.216 & 6.04 & 0.250 & 5.86 \\
\hline HOMEHML (=HML-HMLw) & 0.003 & 0.09 & 0.027 & 0.98 & -0.024 & -0.73 \\
\hline HMLw & -0.037 & -0.79 & 0.017 & 0.43 & -0.054 & -1.15 \\
\hline HOME MOM (=MOM - MOMw) & 0.036 & 0.81 & 0.033 & 0.89 & 0.003 & 0.06 \\
\hline MOMw & 0.028 & 0.60 & 0.027 & 0.67 & 0.002 & 0.03 \\
\hline CONSTANT & -0.001 & -1.18 & -0.001 & -0.99 & 0.000 & -0.34 \\
\hline Adj R2 & 0.890 & & 0.918 & & 0.193 & \\
\hline
\end{tabular}


Table 3: Jensen model with timing (note national only):

\begin{tabular}{|c|c|c|c|c|c|c|}
\hline $\begin{array}{ll}\text { TIMING } & \text { REGRESIONS, } \\
\text { NATIONAL } & \\
\end{array}$ & SRI & & NON SRI & & HEDGE & \\
\hline 1-factor & Coefficient & T-test & Coefficient & T-test & Coefficient & T-test \\
\hline $\mathrm{Rm}-\mathrm{Rf}$ & \begin{tabular}{|l|}
0.785 \\
\end{tabular} & 24.940 & \begin{tabular}{|l|}
0.968 \\
\end{tabular} & 43.230 & -0.184 & \begin{tabular}{|l|l|}
4 & -7.256 \\
\end{tabular} \\
\hline$(\mathrm{Rm}-\mathrm{Rf})^{2}$ & -1.764 & $\mid-3.701$ & -1.038 & -3.059 & -0.726 & \begin{tabular}{|l|}
-1.890 \\
\end{tabular} \\
\hline CONSTANT & 0.002 & 1.130 & 0.000 & 0.404 & 0.001 & \begin{tabular}{|l|l|} 
& 1.047 \\
\end{tabular} \\
\hline Adj R2 & 0.797 & & 0.920 & & 0.238 & \\
\hline 3-factor & Coefficient & T-test & Coefficient & T-test & Coefficient & T-test \\
\hline $\mathrm{Rm}-\mathrm{Rf}$ & \begin{tabular}{|l|}
0.805 \\
\end{tabular} & 32.000 & $\begin{array}{l}0.976 \\
\end{array}$ & 49.290 & -0.171 & \begin{tabular}{|l|l|}
1 & -7.278 \\
\end{tabular} \\
\hline SMB & 0.293 & 8.468 & 0.193 & 7.093 & 0.100 & 3.094 \\
\hline $\mathrm{HML}$ & -0.081 & -2.505 & 0.042 & 1.647 & -0.122 & \begin{tabular}{|l|l|}
2 & -4.075 \\
\end{tabular} \\
\hline$(R m-R f)^{2}$ & -1.256 & -3.277 & -0.682 & -2.260 & -0.574 & \begin{tabular}{|l|l|}
4 & -1.606 \\
\end{tabular} \\
\hline $\mathrm{SMB}^{2}$ & -0.604 & -1.140 & -0.597 & -1.432 & -0.007 & \begin{tabular}{|l|}
$7-0.014$ \\
\end{tabular} \\
\hline $\mathrm{HML}^{2}$ & 1.693 & 5.208 & 1.011 & 3.951 & 0.682 & \begin{tabular}{|l|l|}
2.250 \\
\end{tabular} \\
\hline CONSTANT & 0.000 & 0.287 & 0.000 & -0.405 & 0.001 & 0.649 \\
\hline Adj R2 & 0.874 & & 0.939 & & 0.366 & \\
\hline 4-factor & Coefficient & T-test & Coefficient & T-test & Coefficient & T-test \\
\hline $\mathrm{Rm}-\mathrm{Rf}$ & \begin{tabular}{|l|}
0.813 \\
\end{tabular} & 31.320 & $\begin{array}{l}0.971 \\
\end{array}$ & 46.710 & -0.157 & \begin{tabular}{|l|}
$7-6.502$ \\
\end{tabular} \\
\hline SMB & 0.325 & 8.909 & 0.193 & 6.639 & 0.131 & \begin{tabular}{|l|l|}
1 & 3.865 \\
\end{tabular} \\
\hline $\mathrm{HML}$ & -0.064 & -1.925 & 0.036 & 1.358 & -0.101 & \begin{tabular}{|l|l|}
1 & -3.235 \\
\end{tabular} \\
\hline MOM & 0.050 & 1.302 & -0.023 & -0.742 & 0.072 & 2.036 \\
\hline$(\mathrm{Rm}-\mathrm{Rf})^{2}$ & -1.102 & -2.870 & -0.655 & -2.133 & -0.447 & \begin{tabular}{|l|}
7 \\
\end{tabular} \\
\hline $\mathrm{SMB}^{2}$ & -0.819 & -1.545 & -0.617 & -1.455 & -0.202 & $2-0.409$ \\
\hline $\mathrm{HML}^{2}$ & 1.898 & 5.699 & 1.056 & 3.963 & 0.842 & 2.716 \\
\hline $\mathrm{MOM}^{2}$ & -1.179 & -2.116 & -0.327 & -0.733 & -0.853 & \begin{tabular}{|l|l|}
3 & -1.644 \\
\end{tabular} \\
\hline CONSTANT & 0.001 & 0.768 & 0.000 & -0.085 & 0.001 & 0.898 \\
\hline Adj R2 & 0.877 & & 0.939 & & 0.385 & \\
\hline Conditional 1-factor & Coefficient & T-test & Coefficient & T-test & Coefficient & T-test \\
\hline $\mathrm{Rm}-\mathrm{Rf}$ & \begin{tabular}{|l|}
0.795 \\
\end{tabular} & 22.44 & 0.976 & 38.67 & -0.181 & \begin{tabular}{|l|l|}
1 & -6.53 \\
\end{tabular} \\
\hline$D Y(R m-R f)$ & -0.074 & -0.96 & 0.009 & 0.17 & -0.083 & -1.38 \\
\hline$T B(R m-R f)$ & -0.010 & -0.29 & -0.013 & -0.49 & 0.002 & 0.08 \\
\hline TERM(Rm - Rf) & -0.031 & -0.68 & -0.015 & -0.46 & -0.016 & -0.45 \\
\hline $\mathrm{JAN}(\mathrm{Rm}-\mathrm{Rf})$ & -0.159 & -1.48 & -0.174 & -2.26 & 0.014 & 0.17 \\
\hline CONSTANT & -0.001 & -0.58 & -0.001 & -1.37 & 0.001 & 0.51 \\
\hline Adj R2 & \begin{tabular}{|l|}
0.789 \\
\end{tabular} & & 0.917 & & 0.255 & \\
\hline Conditional 3-factor & Coefficient & T-test & Coefficient & T-test & Coefficient & T-test \\
\hline $\mathrm{Rm}-\mathrm{Rf}$ & \begin{tabular}{|l|}
0.804 \\
\end{tabular} & 26.24 & 0.975 & 42.27 & -0.171 & \begin{tabular}{|l|l|}
1 & -6.62 \\
\end{tabular} \\
\hline SMB & 0.248 & 6.91 & 0.160 & 5.90 & 0.089 & 2.92 \\
\hline $\mathrm{HML}$ & -0.030 & -0.92 & 0.060 & 2.43 & -0.091 & -3.26 \\
\hline$D Y(R m-R f)$ & -0.087 & -1.30 & -0.005 & -0.11 & -0.082 & -1.45 \\
\hline $\mathrm{TB}(\mathrm{Rm}-\mathrm{Rf})$ & -0.005 & -0.15 & -0.008 & -0.34 & 0.003 & 0.13 \\
\hline TERM(Rm - Rf) & -0.027 & -0.67 & -0.012 & -0.41 & -0.014 & -0.43 \\
\hline $\mathrm{JAN}(\mathrm{Rm}-\mathrm{Rf})$ & -0.092 & -0.98 & -0.140 & -1.99 & 0.048 & 0.61 \\
\hline CONSTANT & 0.000 & 0.14 & -0.001 & -1.04 & 0.001 & 1.09 \\
\hline Adj R2 & 0.843 & & 0.931 & & 0.357 & \\
\hline Conditional 4-factor & Coefficient & T-test & Coefficient & T-test & Coefficient & T-test \\
\hline $\mathrm{Rm}-\mathrm{Rf}$ & \begin{tabular}{|l|}
0.814 \\
\end{tabular} & 26.12 & $\begin{array}{l}0.972 \\
\end{array}$ & 41.19 & -0.159 & \begin{tabular}{|l|l|}
9 & -6.09 \\
\end{tabular} \\
\hline
\end{tabular}




\begin{tabular}{|l|r|r|r|r|r|r|}
\hline SMB & 0.263 & 7.10 & 0.156 & 5.56 & 0.107 & 3.45 \\
\hline HML & -0.014 & -0.40 & 0.056 & 2.13 & -0.070 & -2.41 \\
\hline MOM & 0.068 & 1.55 & -0.019 & -0.56 & 0.087 & 2.36 \\
\hline DY(Rm - Rf) & -0.063 & -0.93 & -0.012 & -0.23 & -0.051 & -0.90 \\
\hline TB(Rm - Rf) & -0.017 & -0.55 & -0.004 & -0.19 & -0.013 & -0.49 \\
\hline TERM(Rm - Rf) & -0.041 & -1.01 & -0.008 & -0.27 & -0.033 & -0.97 \\
\hline JAN(Rm - Rf) & -0.088 & -0.94 & -0.141 & -2.00 & 0.053 & 0.68 \\
\hline CONSTANT & 0.000 & -0.11 & -0.001 & -0.93 & 0.001 & 0.72 \\
\hline Adj R2 & 0.845 & & 0.931 & & 0.374 & \\
\hline
\end{tabular}

Note: for international portfolios no timing effects are ever significant 
Table 4: Time varying coefficients

Domestic:

3 factor

\begin{tabular}{||l|r|r|r|r||}
\hline 3 FACTOR & \multicolumn{1}{|c|}{ BETA } & GAMMA & DELTA & ALPHA \\
\hline SRI mean & 0.778917 & 0.352202 & -0.06794 & 0.000972 \\
\hline SRI $p$ & 0.000 & 0.000 & 0.187 & 0.219 \\
\hline Non-SRI mean & 0.96034 & 0.17844 & 0.044741 & -0.0005 \\
\hline Non-SRI $p$ & 0.000 & 0.000 & 0.082 & 0.157 \\
\hline Hedge Mean & -0.18142 & 0.173762 & -0.11268 & 0.001468 \\
\hline Hedge $p$ & 0.000 & 0.002 & 0.006 & .0004732 \\
\hline Hedge change, $2^{\text {nd }}$ period & .1623931 & .1227636 & -.0392513 & .0019134 \\
\hline Hedge change $p$ & 0.000 & 0.070 & 0.486 & 0.0000 \\
\hline \hline
\end{tabular}

4 factor

\begin{tabular}{|l|r|r|r|r|r||}
\hline 4-FACTOR & BETA & GAMMA & DELTA & LAMBDA & ALPHA \\
\hline SRI mean & 0.795184 & 0.381075 & -0.04341 & 0.085172 & 0.001029 \\
\hline SRI $p$ & 0.000 & 0.000 & 0.254 & 0.092 & 0.268 \\
\hline Non-SRI mean & 0.962347 & 0.156682 & 0.037392 & -0.04283 & -0.00031 \\
\hline Non-SRI $p$ & 0.000 & 0.000 & 0.023 & 0.355 & 0.433 \\
\hline Hedge Mean & -0.16716 & 0.224393 & -0.08081 & 0.128 & 0.001342 \\
\hline Hedge $p$ & 0.000 & 0.000 & 0.031 & 0.000 & .0002577 \\
\hline Hedge change, $2^{\text {nd }}$ period & .1609086 & .0399318 & -.0632784 & .0396967 & .0021641 \\
\hline Hedge change $p$ & 0.000 & 0.567 & 0.191 & 0.042 & 0.0000 \\
\hline \hline
\end{tabular}

International

\begin{tabular}{|l|r|r|r|r|r|r|r||}
\hline 3-FACTOR & BETA & GAMMA & DELTA & HOME B & HOME S & HOME H & ALPHA \\
\hline SRI mean & 0.508197 & 0.857764 & 0.293561 & 0.542898 & -0.03286 & -0.01283 & -0.00042 \\
\hline SRI p & 0.000 & 0.000 & 0.000 & 0.000 & 0.175 & 0.575 & 0.613 \\
\hline Non-SRI mean & 0.460533 & 0.927012 & 0.072141 & 0.219392 & 0.036887 & 0.086299 & -0.00255 \\
\hline Non-SRI p & 0.000 & 0.000 & 0.001 & 0.000 & 0.313 & 0.064 & 0.000 \\
\hline Hedge Mean & 0.047664 & -0.06925 & 0.22142 & 0.323506 & -0.06975 & -0.09913 & 0.002135 \\
\hline $\begin{array}{l}\text { Hedge } p \\
\text { Hedge change, } 2^{\text {nd }} \\
\text { period }\end{array}$ & .0 .103 & 0.003 & 0.000 & 0.000 & 0.068 & 0.024 & 0.141 \\
\hline Hedge change $p$ & .127196 & -.060097 & -.009535 & .027723 & .095421 & .029652 & .003064 \\
\hline \hline
\end{tabular}

See also figures 1-6 attached 
Table 5: Average monthly abnormal returns from time-varying model

\begin{tabular}{|c|c|c|c|}
\hline GROUP & $\begin{array}{l}\text { 3 FACTOR } \\
\text { DOMESTIC }\end{array}$ & $\begin{array}{l}4 \text { FACTOR } \\
\text { DOMESTIC }\end{array}$ & \begin{tabular}{|l|} 
3 FACTOR \\
INTERNATIONAL
\end{tabular} \\
\hline SRI mean & $0.20 \%$ & $0.09 \%$ & $0.11 \%$ \\
\hline$p$-value & 0.01 & 0.26 & 0.33 \\
\hline Non-SRI mean & $0.06 \%$ & $0.04 \%$ & $0.03 \%$ \\
\hline$p$-value & 0.16 & 0.34 & 0.68 \\
\hline Difference & $0.14 \%$ & $0.07 \%$ & $0.08 \%$ \\
\hline$p$-value of T-test for difference & 0.15 & 0.62 & 0.53 \\
\hline
\end{tabular}


Table 6: Short horizon Contingency tables of scheme performance - absolute performance

Overall Sample: absolute performance, domestic

\begin{tabular}{|l|r|r|r|r||}
\hline STATISTIC & 1-MONTH & 3-MONTH & 6-MONTH & 12-MONTH \\
\hline PRW & 0.5095908 & 0.4989691 & 0.5492662 & 0.5188679 \\
\hline CP ratio & 1.0687585 & 0.9437504 & 1.4357689 & 1.6927083 \\
\hline SD CP & 0.0715299 & 0.1284508 & 0.1839082 & 0.2777176 \\
\hline$Z$ & 0.4037413 & -0.195739 & 0.8541464 & 0.8230741 \\
\hline Chi & 0.8772379 & 0.2762887 & 3.9308176 & 4.7924528 \\
\hline p Chi & 0.349 & 0.599 & 0.047 & 0.029 \\
\hline \hline
\end{tabular}

Ethicals Sub-sample: absolute performance, domestic

\begin{tabular}{|l|r|r|r|r||}
\hline STATISTIC & 1-MONTH & 3-MONTH & 6-MONTH & 12-MONTH \\
\hline PRW & 0.4875267 & 0.4572748 & 0.4549763 & 0.3655914 \\
\hline CP ratio & 1.1023769 & 1.02 & 1.301627 & 0.9807692 \\
\hline SD CP & 0.1068862 & 0.1926632 & 0.2776732 & 0.4249922 \\
\hline$Z$ & 0.3960298 & 0.0446384 & 0.4123069 & -0.019843 \\
\hline Chi & 2.6421953 & 1.9838337 & 3.957346 & 4.4193548 \\
\hline p Chi & 0.104 & 0.159 & 0.047 & 0.036 \\
\hline \hline
\end{tabular}

Non-Ethicals sub-sample: absolute performance, domestic

\begin{tabular}{|l|r|r|r|r||}
\hline STATISTIC & 1-MONTH & 3-MONTH & 6-MONTH & 12-MONTH \\
\hline PRW & 0.5275362 & 0.5325885 & 0.6240602 & 0.6386555 \\
\hline CP ratio & 1.0381291 & 0.8724969 & 1.500565 & 2.5189394 \\
\hline SD CP & 0.0963614 & 0.1731622 & 0.2475662 & 0.3768401 \\
\hline$Z$ & 0.1686501 & -0.342085 & 0.7119503 & 1.0646897 \\
\hline Chi & 1.9356522 & 3.1489758 & 5.6691729 & 6.3445378 \\
\hline p Chi & $0.164^{* * *}$ & $0.076^{\star * *}$ & $0.017^{* * *}$ & $0.012^{\star * *}$ \\
\hline
\end{tabular}

Schemes are classified as winners or losers based on abnormal returns in each of two consecutive time periods, and the numbers of winner-winner (WW), winner-loser (WL), loser winner (LW) and loser-loser (LL) are counted. The following statistics are computed: a) Percentage of repeat winners, $\mathrm{PRW}=\mathrm{WW} /(\mathrm{N} / 2)$; b) Cross-product ratio $\mathrm{CP}=(\mathrm{WW} \times \mathrm{LL}) /(\mathrm{WL} \times \mathrm{LW})$; where $\log (\mathrm{CP}) / \sigma_{\log (\mathrm{CP})}$ has a standard normal distribution, and $\sigma_{\log (\mathrm{CP})}=\sqrt{ }[(1 / \mathrm{WW})+(1 / \mathrm{WL})+(1 / \mathrm{LW})+(1 / \mathrm{LL})]$; c) Chi-Squared test with 1 d.o.f. where CHI $=\left\{(\mathrm{WW}-\mathrm{N} / 4)^{2}+(\mathrm{WL}-\mathrm{N} / 4)^{2}+(\mathrm{LW}-\mathrm{N} / 4)^{2}(\mathrm{LL}-\right.$ $\left.\mathrm{N} / 4)^{2}\right\} / \mathrm{N} / 4$, and $\mathrm{N}$ is the number of pairs; * denotes ethical/control persistence is significantly above the control/ethical group at the $10 \%$ level; ** denotes ethical/control persistence is significantly above the control/ethical group at the $5 \%$ level; $* * *$ denotes ethical/control persistence is significantly above the control/ethical group at the $1 \%$ level. 
Table 7: Short horizon Contingency tables of scheme performance $-\mathbf{3}$ factor model

Overall Sample: 3 factor domestic

\begin{tabular}{|l|r|r|r|r||}
\hline STATISTIC & 1-MONTH & 3-MONTH & 6-MONTH & 12-MONTH \\
\hline PRW & 0.46948 & 0.4692875 & 0.4887781 & 0.5340909 \\
\hline CP ratio & 0.7902599 & 0.7149733 & 1.0919504 & 1.6491228 \\
\hline SD CP & 0.0777789 & 0.1407141 & 0.1999004 & 0.3040792 \\
\hline$Z$ & -1.314368 & -1.035506 & 0.1911098 & 0.7144618 \\
\hline Chi & 9.1770912 & 5.8820639 & 0.6259352 & 3.0454545 \\
\hline p Chi & 0.002 & 0.015 & 0.429 & 0.081 \\
\hline \hline
\end{tabular}

Ethicals Sub-sample: 3 factor domestic

\begin{tabular}{|l|r|r|r|r||}
\hline STATISTIC & 1-MONTH & 3-MONTH & 6-MONTH & 12-MONTH \\
\hline PRW & 0.467354 & 0.5183099 & 0.5747126 & 0.5405405 \\
\hline CP ratio & 0.8023343 & 0.6917293 & 0.978836 & 1.125 \\
\hline SD CP & 0.1174246 & 0.2142094 & 0.3050554 & 0.4669642 \\
\hline$Z$ & -0.81452 & -0.74723 & -0.030454 & 0.1095427 \\
\hline Chi & 3.6082474 & 5.484507 & 2.045977 & 0.5945946 \\
\hline p Chi & 0.057 & $0.019^{* *}$ & $0.153^{* * *}$ & $0.441^{* *}$ \\
\hline \hline
\end{tabular}

Non-Ethicals sub-sample: 3 factor domestic

\begin{tabular}{|l|r|r|r|r||}
\hline STATISTIC & 1-MONTH & 3-MONTH & 6-MONTH & 12-MONTH \\
\hline PRW & 0.4711409 & 0.4313725 & 0.4229075 & 0.5294118 \\
\hline CP ratio & 0.7809076 & 0.7213115 & 1.1313131 & 2.1961722 \\
\hline SD CP & 0.1038245 & 0.1875175 & 0.2679914 & 0.405629 \\
\hline$Z$ & -1.034441 & -0.756608 & 0.1999424 & 0.8423125 \\
\hline Chi & 5.704698 & 3.788671 & 4.6299559 & 5.0588235 \\
\hline p Chi & 0.017 & 0.052 & 0.031 & 0.025 \\
\hline
\end{tabular}

Schemes are classified as winners or losers based on abnormal returns in each of two consecutive time periods, and the numbers of winner-winner (WW), winner-loser (WL), loser winner (LW) and loser-loser (LL) are counted. The following statistics are computed: a) Percentage of repeat winners, $\mathrm{PRW}=\mathrm{WW} /(\mathrm{N} / 2)$; b) Cross-product ratio $\mathrm{CP}=(\mathrm{WW} \times \mathrm{LL}) /(\mathrm{WL} \times \mathrm{LW})$; where $\log (\mathrm{CP}) / \sigma_{\log (\mathrm{CP})}$ has a standard normal distribution, and $\sigma_{\log (\mathrm{CP})}=\sqrt{ }[(1 / \mathrm{WW})+(1 / \mathrm{WL})+(1 / \mathrm{LW})+(1 / \mathrm{LL})]$; c) Chi-Squared test with 1 d.o.f. where CHI $=\left\{(\mathrm{WW}-\mathrm{N} / 4)^{2}+(\mathrm{WL}-\mathrm{N} / 4)^{2}+(\mathrm{LW}-\mathrm{N} / 4)^{2}(\mathrm{LL}-\right.$ $\left.\mathrm{N} / 4)^{2}\right\} / \mathrm{N} / 4$, and $\mathrm{N}$ is the number of pairs; * denotes ethical/control persistence is significantly above the control/ethical group at the $10 \%$ level; ** denotes ethical/control persistence is significantly above the control/ethical group at the $5 \%$ level; $* * *$ denotes ethical/control persistence is significantly above the control/ethical group at the $1 \%$ level. 
Table 8: Short horizon Contingency tables of scheme performance -4 factor model

Overall Sample: 4 factor domestic

\begin{tabular}{|l|r|r|r|r||}
\hline STATISTIC & 1-MONTH & 3-MONTH & 6-MONTH & 12-MONTH \\
\hline PRW & 0.4807837 & 0.4373464 & 0.4588529 & 0.6363636 \\
\hline CP ratio & 0.8445789 & 0.647591 & 0.8424908 & 3.5526882 \\
\hline SD CP & 0.0777138 & 0.1410412 & 0.2000219 & 0.316856 \\
\hline$Z$ & -0.943973 & -1.337902 & -0.372133 & 1.7375627 \\
\hline Chi & 4.7460437 & 9.6363636 & 1.0448878 & 16.681818 \\
\hline p Chi & 0.029 & 0.002 & 0.307 & 0.000 \\
\hline \hline
\end{tabular}

Ethicals Sub-sample: 4 factor domestic

\begin{tabular}{|l|r|r|r|r||}
\hline STATISTIC & 1-MONTH & 3-MONTH & 6-MONTH & 12-MONTH \\
\hline PRW & 0.475945 & 0.4619718 & 0.5172414 & 0.6216216 \\
\hline CP ratio & 0.9646862 & 0.5991392 & 1.0963455 & 1.7137255 \\
\hline SD CP & 0.1172935 & 0.2142703 & 0.3033395 & 0.4707441 \\
\hline$Z$ & -0.133118 & -1.038278 & 0.1316922 & 0.4969605 \\
\hline Chi & 0.9965636 & 6.3633803 & 0.1149425 & 1.8918919 \\
\hline p Chi & 0.318 & $0.012^{*}$ & $0.735^{*}$ & 0.169 \\
\hline
\end{tabular}

Non-Ethicals sub-sample: 4 factor domestic

\begin{tabular}{|l|r|r|r|r||}
\hline STATISTIC & 1-MONTH & 3-MONTH & 6-MONTH & 12-MONTH \\
\hline PRW & 0.4845638 & 0.4183007 & 0.4140969 & 0.6470588 \\
\hline CP ratio & 0.7589013 & 0.6829268 & 0.6847034 & 6.3461538 \\
\hline SD CP & 0.1039144 & 0.1878505 & 0.2671924 & 0.4412778 \\
\hline$Z$ & -1.153013 & -0.881689 & -0.615652 & 1.8186063 \\
\hline Chi & 8.0348993 & 5.2527233 & 2.6563877 & 20.117647 \\
\hline p Chi & $0.005^{\star * *}$ & 0.022 & 0.103 & $0.000^{\star * *}$ \\
\hline
\end{tabular}

Schemes are classified as winners or losers based on abnormal returns in each of two consecutive time periods, and the numbers of winner-winner (WW), winner-loser (WL), loser winner (LW) and loser-loser (LL) are counted. The following statistics are computed: a) Percentage of repeat winners, $\mathrm{PRW}=\mathrm{WW} /(\mathrm{N} / 2)$; b) Cross-product ratio $\mathrm{CP}=(\mathrm{WW} \times \mathrm{LL}) /(\mathrm{WL} \times \mathrm{LW})$; where $\log (\mathrm{CP}) / \sigma_{\log (\mathrm{CP})}$ has a standard normal distribution, and $\sigma_{\log (\mathrm{CP})}=\sqrt{ }[(1 / \mathrm{WW})+(1 / \mathrm{WL})+(1 / \mathrm{LW})+(1 / \mathrm{LL})]$; c) Chi-Squared test with 1 d.o.f. where CHI $=\left\{(\mathrm{WW}-\mathrm{N} / 4)^{2}+(\mathrm{WL}-\mathrm{N} / 4)^{2}+(\mathrm{LW}-\mathrm{N} / 4)^{2}(\mathrm{LL}-\right.$ $\left.\mathrm{N} / 4)^{2}\right\} / \mathrm{N} / 4$, and $\mathrm{N}$ is the number of pairs; * denotes ethical/control persistence is significantly above the control/ethical group at the $10 \%$ level; ** denotes ethical/control persistence is significantly above the control/ethical group at the $5 \%$ level; $* * *$ denotes ethical/control persistence is significantly above the control/ethical group at the $1 \%$ level. 
Table 9: Short horizon Contingency tables of scheme performance - absolute performance, international

Overall Sample: absolute performance, international

\begin{tabular}{|l|r|r|r|r||}
\hline STATISTIC & 1-MONTH & 3-MONTH & 6-MONTH & 12-MONTH \\
\hline PRW & 0.4961581 & 0.5224396 & 0.5336427 & 0.5771144 \\
\hline CP ratio & 0.9725739 & 1.2078695 & 1.1482988 & 1.86268 \\
\hline SD CP & 0.0765157 & 0.1358421 & 0.1928359 & 0.2855663 \\
\hline$Z$ & -0.157842 & 0.6037892 & 0.3114302 & 0.9459739 \\
\hline Chi & 0.1328211 & 1.9367089 & 0.74942 & 4.7910448 \\
\hline p Chi & 0.716 & 0.164 & 0.387 & 0.029 \\
\hline \hline
\end{tabular}

Ethicals Sub-sample: absolute performance, international

\begin{tabular}{|l|r|r|r|r||}
\hline STATISTIC & 1-MONTH & 3-MONTH & 6-MONTH & 12-MONTH \\
\hline PRW & 0.460443 & 0.52 & 0.5076142 & 0.4888889 \\
\hline CP ratio & 0.8627769 & 1.3768322 & 1.352657 & 2.0058824 \\
\hline SD CP & 0.1126409 & 0.2007321 & 0.2860393 & 0.4318983 \\
\hline$Z$ & -0.569078 & 0.6918725 & 0.4586351 & 0.6999459 \\
\hline Chi & 2.8291139 & 2.96 & 1.5177665 & 4.8444444 \\
\hline p Chi & 0.093 & 0.085 & 0.218 & 0.028 \\
\hline \hline
\end{tabular}

Non-Ethicals sub-sample: absolute performance, international

\begin{tabular}{|l|r|r|r|r||}
\hline STATISTIC & 1-MONTH & 3-MONTH & 6-MONTH & 12-MONTH \\
\hline PRW & 0.526889 & 0.5245203 & 0.5555556 & 0.6486486 \\
\hline CP ratio & 1.075 & 1.0791922 & 0.9877265 & 1.6904348 \\
\hline SD CP & 0.1044123 & 0.18479 & 0.2623088 & 0.3850884 \\
\hline Z & 0.300812 & 0.1791157 & -0.020447 & 0.5920677 \\
\hline Chi & 1.4179714 & 0.4498934 & 1.4529915 & 3.5585586 \\
\hline p Chi & $0.234^{* * *}$ & $0.502^{*}$ & $0.228^{* *}$ & $0.059^{* *}$ \\
\hline
\end{tabular}

Schemes are classified as winners or losers based on abnormal returns in each of two consecutive time periods, and the numbers of winner-winner (WW), winner-loser (WL), loser winner (LW) and loser-loser (LL) are counted. The following statistics are computed: a) Percentage of repeat winners, $\mathrm{PRW}=\mathrm{WW} /(\mathrm{N} / 2)$; b) Cross-product ratio $\mathrm{CP}=(\mathrm{WW} \times \mathrm{LL}) /(\mathrm{WL} \times \mathrm{LW})$; where $\log (\mathrm{CP}) / \sigma_{\log (\mathrm{CP})}$ has a standard normal distribution, and $\sigma_{\log (\mathrm{CP})}=\sqrt{ }[(1 / \mathrm{WW})+(1 / \mathrm{WL})+(1 / \mathrm{LW})+(1 / \mathrm{LL})]$; c) Chi-Squared test with 1 d.o.f. where $\mathrm{CHI}=\left\{(\mathrm{WW}-\mathrm{N} / 4)^{2}+(\mathrm{WL}-\mathrm{N} / 4)^{2}+(\mathrm{LW}-\mathrm{N} / 4)^{2}(\mathrm{LL}-\right.$ $\left.\mathrm{N} / 4)^{2}\right\} / \mathrm{N} / 4$, and $\mathrm{N}$ is the number of pairs; * denotes ethical/control persistence is significantly above the control/ethical group at the $10 \%$ level; ** denotes ethical/control persistence is significantly above the control/ethical group at the $5 \%$ level; $* * *$ denotes ethical/control persistence is significantly above the control/ethical group at the $1 \%$ level. 
Table 10: Short horizon Contingency tables of scheme performance - multifactor model, international

Overall Sample: multi-factor international

\begin{tabular}{|l|r|r|r|r||}
\hline STATISTIC & 1-MONTH & 3-MONTH & 6-MONTH & 12-MONTH \\
\hline PRW & 0.4700565 & 0.460396 & 0.5429234 & 0.5572139 \\
\hline CP ratio & 0.8532325 & 0.7725857 & 1.3590909 & 1.7167019 \\
\hline SD CP & 0.0776995 & 0.141022 & 0.1932451 & 0.2847483 \\
\hline$Z$ & -0.887169 & -0.794581 & 0.6895311 & 0.8242187 \\
\hline Chi & 4.7016949 & 3.4455446 & 2.549884 & 3.6766169 \\
\hline p Chi & 0.030 & 0.063 & 0.110 & 0.055 \\
\hline \hline
\end{tabular}

Ethicals Sub-sample: multi-factor international

\begin{tabular}{|l|r|r|r|r||}
\hline STATISTIC & 1-MONTH & 3-MONTH & 6-MONTH & 12-MONTH \\
\hline PRW & 0.4669528 & 0.5055556 & 0.5177665 & 0.4888889 \\
\hline CP ratio & 0.8619015 & 0.7431764 & 1.5278926 & 2.0058824 \\
\hline SD CP & 0.1172999 & 0.2118637 & 0.2868863 & 0.4318983 \\
\hline$Z$ & -0.550234 & -0.608448 & 0.6416925 & 0.6999459 \\
\hline Chi & 2.0901288 & 3.2666667 & 2.7360406 & 4.8444444 \\
\hline p Chi & 0.148 & $0.071^{* *}$ & 0.098 & 0.028 \\
\hline
\end{tabular}

Non-Ethicals sub-sample: multi-factor international

\begin{tabular}{|l|r|r|r|r||}
\hline STATISTIC & 1-MONTH & 3-MONTH & 6-MONTH & 12-MONTH \\
\hline PRW & 0.4241071 & 0.4264392 & 0.5641026 & 0.6126126 \\
\hline CP ratio & 0.7849003 & 0.8132231 & 1.2214286 & 1.4711538 \\
\hline SD CP & 0.1898087 & 0.1854577 & 0.2621723 & 0.3828538 \\
\hline$Z$ & -0.554166 & -0.484155 & 0.3313396 & 0.4379168 \\
\hline Chi & 3.5178571 & 3.4520256 & 1.3162393 & 2.045045 \\
\hline p Chi & 0.061 & 0.063 & $0.251^{*}$ & $0.153^{\star *}$ \\
\hline
\end{tabular}

Schemes are classified as winners or losers based on abnormal returns in each of two consecutive time periods, and the numbers of winner-winner (WW), winner-loser (WL), loser winner (LW) and loser-loser (LL) are counted. The following statistics are computed: a) Percentage of repeat winners, $\mathrm{PRW}=\mathrm{WW} /(\mathrm{N} / 2)$; b) Cross-product ratio $\mathrm{CP}=(\mathrm{WW} \times \mathrm{LL}) /(\mathrm{WL} \times \mathrm{LW})$; where $\log (\mathrm{CP}) / \sigma_{\log (\mathrm{CP})}$ has a standard normal distribution, and $\sigma_{\log (\mathrm{CP})}=\sqrt{ }[(1 / \mathrm{WW})+(1 / \mathrm{WL})+(1 / \mathrm{LW})+(1 / \mathrm{LL})]$; c) Chi-Squared test with 1 d.o.f. where $\mathrm{CHI}=\left\{(\mathrm{WW}-\mathrm{N} / 4)^{2}+(\mathrm{WL}-\mathrm{N} / 4)^{2}+(\mathrm{LW}-\mathrm{N} / 4)^{2}(\mathrm{LL}-\right.$ $\left.\mathrm{N} / 4)^{2}\right\} / \mathrm{N} / 4$, and $\mathrm{N}$ is the number of pairs; * denotes ethical/control persistence is significantly above the control/ethical group at the $10 \%$ level; ** denotes ethical/control persistence is significantly above the control/ethical group at the $5 \%$ level; $* * *$ denotes ethical/control persistence is significantly above the control/ethical group at the $1 \%$ level. 
Table 11: Performance conditioned on prior 12 months' abnormal performance -3 factor model

\begin{tabular}{|c|c|c|c|c|c|c|}
\hline QUARTILE & \multicolumn{2}{|c|}{ OVERALL } & \multicolumn{2}{|l|}{ SRI } & \multicolumn{2}{|c|}{ NON-SRI } \\
\hline Q1 & Coef't & T-ratio & Coef't & T-ratio & Coef't & T-ratio \\
\hline $\mathrm{Rm}-\mathrm{Rf}$ & 0.872 & 18.23 & 0.806 & 12.4 & 0.917 & 19.49 \\
\hline SMB & 0.229 & 4.199 & 0.225 & 3.037 & 0.239 & 4.455 \\
\hline HML & -0.105 & -2.234 & -0.133 & -2.095 & -0.05 & -1.092 \\
\hline CONSTANT & 0.002 & 1.026 & 0.002 & 0.823 & 0.001 & 0.576 \\
\hline Adusted R2 & & 0.747 & & 0.586 & & 0.791 \\
\hline $\mathrm{Q} 2$ & Coeft' & T-ratio & Coef't & T-ratio & Coef't & T-ratio \\
\hline $\mathrm{Rm}-\mathrm{Rf}$ & 0.942 & 34.35 & 0.921 & 19.24 & 0.976 & 39.22 \\
\hline SMB & 0.153 & 4.885 & 0.224 & 4.174 & 0.113 & 4.018 \\
\hline HML & 0.037 & 1.362 & 0.063 & 1.261 & 0.038 & 1.567 \\
\hline CONSTANT & 0 & -0.353 & 0 & -0.23 & -0.001 & -0.882 \\
\hline Adusted R2 & & 0.909 & & 0.793 & & 0.932 \\
\hline Q3 & Coeft & T-ratio & Coef't & T-ratio & Coeft't & T-ratio \\
\hline $\mathrm{Rm}-\mathrm{Rf}$ & 0.92 & 37.49 & 0.916 & 21.76 & 0.933 & 39.2 \\
\hline SMB & 0.089 & 3.192 & 0.189 & 3.836 & 0.044 & 1.619 \\
\hline HML & 0.068 & 2.833 & 0.105 & 2.314 & 0.06 & 2.556 \\
\hline CONSTANT & -0.001 & -1.173 & -0.002 & -1.377 & 0 & -0.393 \\
\hline Adusted R2 & & 0.923 & & 0.835 & & 0.929 \\
\hline $\mathrm{Q} 4$ & Coeft' & T-ratio & Coef't & T-ratio & Coef't & T-ratio \\
\hline $\mathrm{Rm}-\mathrm{Rf}$ & 0.864 & 31.99 & 0.753 & 20.82 & 0.913 & 33.02 \\
\hline SMB & 0.149 & 4.846 & 0.243 & 6.093 & 0.081 & 2.564 \\
\hline HML & 0.095 & 3.583 & 0.095 & 2.823 & 0.139 & 5.158 \\
\hline CONSTANT & -0.002 & -1.685 & -0.004 & -2.67 & -0.002 & -1.743 \\
\hline Adusted R2 & & 0.898 & & 0.811 & & 0.905 \\
\hline $\mathrm{W}-\mathrm{L}$ & Coeft & T-ratio & Coeft & T-ratio & Coeft' & T-ratio \\
\hline $\mathrm{Rm}-\mathrm{Rf}$ & 0.008 & 0.174 & 0.022 & 0.318 & 0.02 & 0.362 \\
\hline SMB & 0.08 & 1.512 & -0.057 & -0.761 & 0.154 & 2.5 \\
\hline HML & -0.199 & -4.401 & -0.231 & -3.645 & -0.179 & -3.4 \\
\hline CONSTANT & 0.004 & 2.044 & 0.007 & 2.687 & 0.004 & 1.544 \\
\hline Adusted R2 & & 0.19 & & 0.095 & & 0.197 \\
\hline
\end{tabular}

Q1-Q4 denotes prior performance quartile (Q1 is highest, Q4 lowest). W-L is "winner" (highest quartile prior performance) minus "loser" (lowest quartile prior performance) or "hedge" portfolio performance. 
Table 12: Performance conditioned on prior 12 months' abnormal performance -4 factor model

\begin{tabular}{|c|c|c|c|c|c|c|}
\hline QUARTILE & \multicolumn{2}{|c|}{ OVERALL } & \multicolumn{2}{|l|}{ SRI } & \multicolumn{2}{|c|}{ NON-SRI } \\
\hline $\mathrm{Q} 1$ & Coeft & T-ratio & Coeft & T-ratio & Coeft & T-ratio \\
\hline $\mathrm{Rm}-\mathrm{Rf}$ & 0.914 & 19.09 & 0.849 & 12.23 & 0.937 & 20.28 \\
\hline SMB & 0.261 & 4.903 & 0.216 & 2.799 & 0.273 & 5.278 \\
\hline HML & -0.057 & -1.217 & -0.114 & -1.676 & 0.036 & 0.801 \\
\hline WML & 0.111 & 1.814 & 0.114 & 1.282 & 0.098 & 1.672 \\
\hline CONSTANT & 0.001 & 0.698 & 0.002 & 0.804 & 0 & -0.097 \\
\hline Adusted R2 & & 0.769 & & 0.581 & & 0.802 \\
\hline Q2 & Coeft & T-ratio & Coeft & T-ratio & Coeft & T-ratio \\
\hline $\mathrm{Rm}-\mathrm{Rf}$ & 0.889 & 27.88 & 0.83 & 13.85 & 0.931 & 30.14 \\
\hline SMB & 0.149 & 4.207 & 0.234 & 3.771 & 0.078 & 2.325 \\
\hline HML & 0.013 & 0.416 & 0.025 & 0.443 & 0.013 & 0.425 \\
\hline WML & -0.039 & -0.955 & -0.046 & -0.559 & -0.03 & -0.764 \\
\hline CONSTANT & 0.001 & 0.898 & 0.001 & 0.63 & 0.001 & 0.9 \\
\hline Adusted R2 & & 0.878 & & 0.675 & & 0.903 \\
\hline Q3 & Coeft & T-ratio & Coeft & T-ratio & Coeft & T-ratio \\
\hline $\mathrm{Rm}-\mathrm{Rf}$ & 0.92 & 40.02 & 0.892 & 24.22 & 0.926 & 40.37 \\
\hline SMB & 0.1 & 3.91 & 0.235 & 5.688 & 0.033 & 1.297 \\
\hline HML & 0.057 & 2.525 & 0.092 & 2.508 & 0.043 & 1.909 \\
\hline WML & -0.019 & -0.646 & 0.042 & 0.881 & -0.025 & -0.853 \\
\hline CONSTANT & -0.002 & -2.025 & -0.004 & -2.728 & -0.001 & -1.093 \\
\hline Adusted R2 & & 0.936 & & 0.865 & & 0.938 \\
\hline $\mathrm{Q} 4$ & Coeft & T-ratio & Coeft & T-ratio & Coeft & T-ratio \\
\hline $\mathrm{Rm}-\mathrm{Rf}$ & 0.874 & 30.84 & 0.797 & 20.59 & 0.903 & 30.43 \\
\hline SMB & 0.118 & 3.748 & 0.18 & 4.348 & 0.054 & 1.654 \\
\hline HML & 0.07 & 2.511 & 0.07 & 1.942 & 0.068 & 2.34 \\
\hline WML & -0.05 & -1.385 & -0.023 & -0.496 & -0.151 & -3.994 \\
\hline CONSTANT & -0.002 & -1.467 & -0.003 & -2.015 & -0.001 & -0.712 \\
\hline Adusted R2 & & 0.899 & & 0.816 & & 0.905 \\
\hline W-L & Coeft & T-ratio & Coeft't & T-ratio & Coeft & T-ratio \\
\hline $\mathrm{Rm}-\mathrm{Rf}$ & 0.039 & 0.902 & 0.028 & 0.39 & 0.034 & 0.688 \\
\hline SMB & 0.143 & 2.95 & -0.01 & -0.134 & 0.216 & 3.903 \\
\hline HML & -0.127 & -2.974 & -0.193 & -2.855 & -0.03 & -0.624 \\
\hline WML & 0.161 & 2.897 & 0.131 & 1.49 & 0.253 & 4.063 \\
\hline CONSTANT & 0.003 & 1.723 & 0.007 & 2.512 & 0 & 0.241 \\
\hline Adusted R2 & & 0.246 & & 0.095 & & 0.259 \\
\hline
\end{tabular}

Q1-Q4 denotes prior performance quartile (Q1 is highest, Q4 lowest). W-L is "winner" (highest quartile prior performance) minus "loser" (lowest quartile prior performance) or "hedge" portfolio performance. 
Table 13: Performance conditioned on prior 12 months' absolute performance $-1,3$ and 4 factor models

\begin{tabular}{|c|c|c|c|c|c|c|c|c|c|c|c|c|c|c|c|c|c|c|}
\hline \multirow[b]{3}{*}{ Q1 } & \multicolumn{6}{|c|}{ 1-FACTOR } & \multicolumn{6}{|l|}{ 3-FACTOR } & \multicolumn{6}{|l|}{ 4-FACTOR } \\
\hline & \multicolumn{2}{|c|}{ OVERALL } & \multicolumn{2}{|l|}{ SRI } & \multicolumn{2}{|c|}{ NON-SRI } & \multicolumn{2}{|l|}{ OVERALL } & \multicolumn{2}{|l|}{ SRI } & \multicolumn{2}{|c|}{ NON-SRI } & \multicolumn{2}{|l|}{ OVERALL } & \multicolumn{2}{|l|}{ SRI } & \multicolumn{2}{|c|}{ NON-SRI } \\
\hline & 0.903 & 18.93 & 0.858 & 12.89 & 0.903 & 22.71 & 0.915 & 20.65 & 0.873 & 13.94 & 0.911 & 23.99 & 0.954 & 21.57 & 0.918 & 14.52 & 0.936 & 24.27 \\
\hline Rm-Rf & & & & & & & 0.136 & 2.70 & 0.133 & 1.88 & 0.123 & 2.83 & 0.161 & 3.28 & 0.162 & 2.32 & 0.139 & 3.23 \\
\hline SMB & & & & & & & -0.106 & -2.45 & -0.164 & -2.68 & -0.041 & -1.10 & -0.066 & -1.51 & -0.116 & -1.86 & -0.015 & -0.38 \\
\hline HML & & & & & & & & & & & & & 0.184 & 3.25 & 0.213 & 2.67 & 0.119 & 2.41 \\
\hline WML & 0.002 & 0.87 & 0.003 & 1.05 & 0.001 & 0.32 & 0.002 & 1.38 & 0.004 & 1.50 & 0.001 & 0.60 & 0.002 & 1.10 & 0.003 & 1.28 & 0.001 & 0.36 \\
\hline CONSTANT & & 0.75 & & 0.59 & & 0.82 & & 0.79 & & 0.64 & & 0.83 & & 0.80 & & 0.66 & & 0.84 \\
\hline Adusted R2 & Coef't & T-ratio & Coef't & $\begin{array}{l}\text { T- } \\
\text { ratio }\end{array}$ & Coef't & $\begin{array}{l}\begin{array}{l}\mathrm{T}- \\
\text { ratio }\end{array}\end{array}$ & Coef't & $\begin{array}{l}\text { T- } \\
\text { ratio }\end{array}$ & Coef't & $\begin{array}{l}\text { T- } \\
\text { ratio }\end{array}$ & Coef't & T-ratio & Coef't & $\begin{array}{l}\text { T- } \\
\text { ratio }\end{array}$ & Coef't & $\begin{array}{l}\mathrm{T}- \\
\text { ratio }\end{array}$ & Coef't & T-ratio \\
\hline $\mathrm{Q} 2$ & 0.946 & 31.42 & 0.957 & 18.82 & 0.97 & 30.86 & 0.954 & 34.15 & 0.964 & 21.21 & 0.975 & 31.70 & 0.963 & 33.23 & 0.961 & 19.89 & 0.99 & 31.30 \\
\hline Rm - Rf & & & & & & & 0.114 & 3.57 & 0.2 & 3.97 & 0.079 & 2.25 & 0.119 & 3.70 & 0.198 & 3.87 & 0.089 & 2.52 \\
\hline SMB & & & & & & & -0.039 & -1.44 & -0.046 & -1.12 & -0.019 & -0.64 & -0.031 & -1.07 & -0.049 & -1.12 & -0.004 & -0.11 \\
\hline HML & & & & & & & & & & & & & 0.04 & 1.07 & -0.011 & -0.20 & 0.071 & 1.75 \\
\hline WML & 0 & -0.35 & 0 & -0.04 & 0 & 0.12 & 0 & $\begin{array}{l}-0.01 \\
\end{array}$ & 0 & 0.09 & 0 & 0.33 & 0 & -0.12 & 0 & 0.10 & 0 & 0.16 \\
\hline CONSTANT & & 0.892 & & 0.792 & & 0.890 & & 0.908 & & 0.834 & & 0.895 & & 0.908 & & 0.832 & & 0.897 \\
\hline Adusted R2 & Coef't & T-ratio & Coef't & $\begin{array}{l}\text { T- } \\
\text { ratio }\end{array}$ & Coef't & $\begin{array}{l}\begin{array}{l}\mathrm{T}- \\
\text { ratio }\end{array}\end{array}$ & Coef't & $\begin{array}{l}\text { T- } \\
\text { ratio }\end{array}$ & Coef't & $\begin{array}{l}\begin{array}{l}\text { T- } \\
\text { ratio }\end{array} \\
\end{array}$ & Coef't & T-ratio & Coef't & $\begin{array}{l}\text { T- } \\
\text { ratio }\end{array}$ & Coef't & $\begin{array}{l}\text { T- } \\
\text { ratio }\end{array}$ & Coef't & T-ratio \\
\hline Q3 & 0.926 & 31.13 & 0.899 & 19.61 & 0.943 & 35.21 & 0.931 & 33.74 & 0.901 & 21.96 & 0.946 & 36.67 & 0.925 & 32.26 & 0.889 & 21.09 & 0.947 & 35.24 \\
\hline $\mathrm{Rm}-\mathrm{Rf}$ & & & & & & & 0.145 & 4.61 & 0.247 & 5.31 & 0.097 & 3.30 & 0.141 & 4.42 & 0.237 & 5.04 & 0.098 & 3.28 \\
\hline SMB & & & & & & & 0.062 & 2.29 & 0.091 & 2.29 & 0.051 & 2.01 & 0.055 & 1.95 & 0.077 & 1.88 & 0.052 & 1.97 \\
\hline HML & & & & & & & & & & & & & -0.03 & -0.82 & -0.064 & -1.19 & 0.006 & 0.18 \\
\hline WML & -0.001 & -1.23 & -0.003 & -1.37 & -0.001 & -0.94 & -0.002 & -1.36 & -0.003 & -1.60 & -0.001 & -1.05 & -0.001 & -1.27 & -0.003 & -1.49 & -0.001 & -1.06 \\
\hline CONSTANT & & 0.891 & & 0.780 & & 0.912 & & 0.906 & & 0.824 & & 0.919 & & 0.906 & & 0.825 & & 0.918 \\
\hline Adusted R2 & Coef't & T-ratio & Coef't & $\begin{array}{l}\mathrm{T}- \\
\text { ratio }\end{array}$ & Coef't & $\begin{array}{l}\mathrm{T}- \\
\text { ratio }\end{array}$ & Coeft & $\begin{array}{l}\text { T- } \\
\text { ratio }\end{array}$ & Coef't & $\begin{array}{l}\text { T- } \\
\text { ratio }\end{array}$ & Coef't & T-ratio & Coeft' & $\begin{array}{l}\text { T- } \\
\text { ratio }\end{array}$ & Coef't & $\begin{array}{l}\mathrm{T}- \\
\text { ratio } \\
\end{array}$ & Coef't & T-ratio \\
\hline $\mathrm{Q} 4$ & 0.844 & 23.14 & 0.772 & 17.62 & 1.002 & 26.75 & 0.849 & 25.74 & 0.779 & 19.01 & 0.995 & 27.66 & 0.824 & 24.77 & 0.761 & 18.02 & 0.956 & 26.86 \\
\hline $\mathrm{Rm}-\mathrm{Rf}$ & & & & & & & 0.188 & 5.01 & 0.203 & 4.35 & 0.111 & 2.81 & 0.173 & 4.66 & 0.192 & 4.08 & 0.093 & 2.48 \\
\hline SMB & & & & & & & 0.119 & 3.68 & 0.091 & 2.27 & 0.089 & 2.70 & 0.093 & 2.84 & 0.072 & 1.73 & 0.058 & 1.78 \\
\hline HML & & & & & & & & & & & & & -0.117 & -2.75 & -0.086 & -1.60 & -0.15 & -3.57 \\
\hline WML & -0.002 & -1.38 & -0.003 & -1.45 & -0.001 & -0.84 & -0.002 & -1.71 & -0.003 & -1.59 & -0.002 & -1.16 & -0.002 & -1.47 & -0.002 & $\begin{array}{ll}-1.43 \\
\end{array}$ & -0.001 & -1.01 \\
\hline CONSTANT & & 0.818 & & 0.722 & & 0.879 & & 0.852 & & 0.758 & & 0.889 & & 0.860 & & 0.761 & & 0.902 \\
\hline Adusted R2 & Coef't & T-ratio & Coef't & $\begin{array}{l}\mathrm{T}- \\
\text { ratio }\end{array}$ & Coef't & $\begin{array}{l}\mathrm{T}- \\
\text { ratio }\end{array}$ & Coeft & $\begin{array}{l}\text { T- } \\
\text { ratio }\end{array}$ & Coef't & $\begin{array}{l}\mathrm{T}- \\
\text { ratio }\end{array}$ & Coef't & T-ratio & Coeft & $\begin{array}{l}\text { T- } \\
\text { ratio }\end{array}$ & Coeft' & $\begin{array}{l}\mathrm{T}- \\
\text { ratio }\end{array}$ & Coef't & T-ratio \\
\hline W-L & 0.059 & 1.12 & 0.073 & 1.04 & -0.103 & -1.93 & 0.067 & 1.37 & 0.084 & 1.27 & -0.092 & -1.80 & 0.129 & 2.83 & 0.146 & 2.24 & -0.023 & -0.48 \\
\hline $\mathrm{Rm}-\mathrm{Rf}$ & & & & & & & -0.052 & -0.94 & -0.064 & -0.85 & 0.029 & 0.51 & -0.012 & -0.23 & -0.023 & -0.32 & 0.06 & 1.18 \\
\hline SMB & & & & & & & -0.225 & -4.73 & -0.248 & -3.86 & -0.128 & -2.72 & -0.159 & -3.54 & -0.181 & -2.84 & -0.071 & -1.62 \\
\hline HML & & & & & & & & & & & & & 0.301 & 5.16 & 0.299 & 3.64 & 0.271 & 4.74 \\
\hline WML & 0.004 & 1.74 & 0.005 & 1.89 & 0.002 & 0.88 & 0.005 & 2.42 & 0.006 & 2.37 & 0.003 & 1.33 & 0.004 & 2.14 & 0.005 & 2.13 & 0.002 & 1.18 \\
\hline CONSTANT & & 0.002 & & 0.001 & & 0.028 & & 0.154 & & 0.106 & & 0.110 & & 0.307 & & 0.195 & & 0.280 \\
\hline
\end{tabular}


\begin{tabular}{|l|l|l|l|l|l|l|l|l|l|l|l|l|l|l|l|l|l|l|}
\hline \hline Adusted R2 & 0.903 & 18.93 & 0.858 & 12.89 & 0.903 & 22.71 & 0.915 & 20.65 & 0.873 & 13.94 & 0.911 & 23.99 & 0.954 & 21.57 & 0.918 & 14.52 & 0.936 & 24.27 \\
\hline \hline
\end{tabular} 
Calendar Time 3-Factor Alphas - Domestic

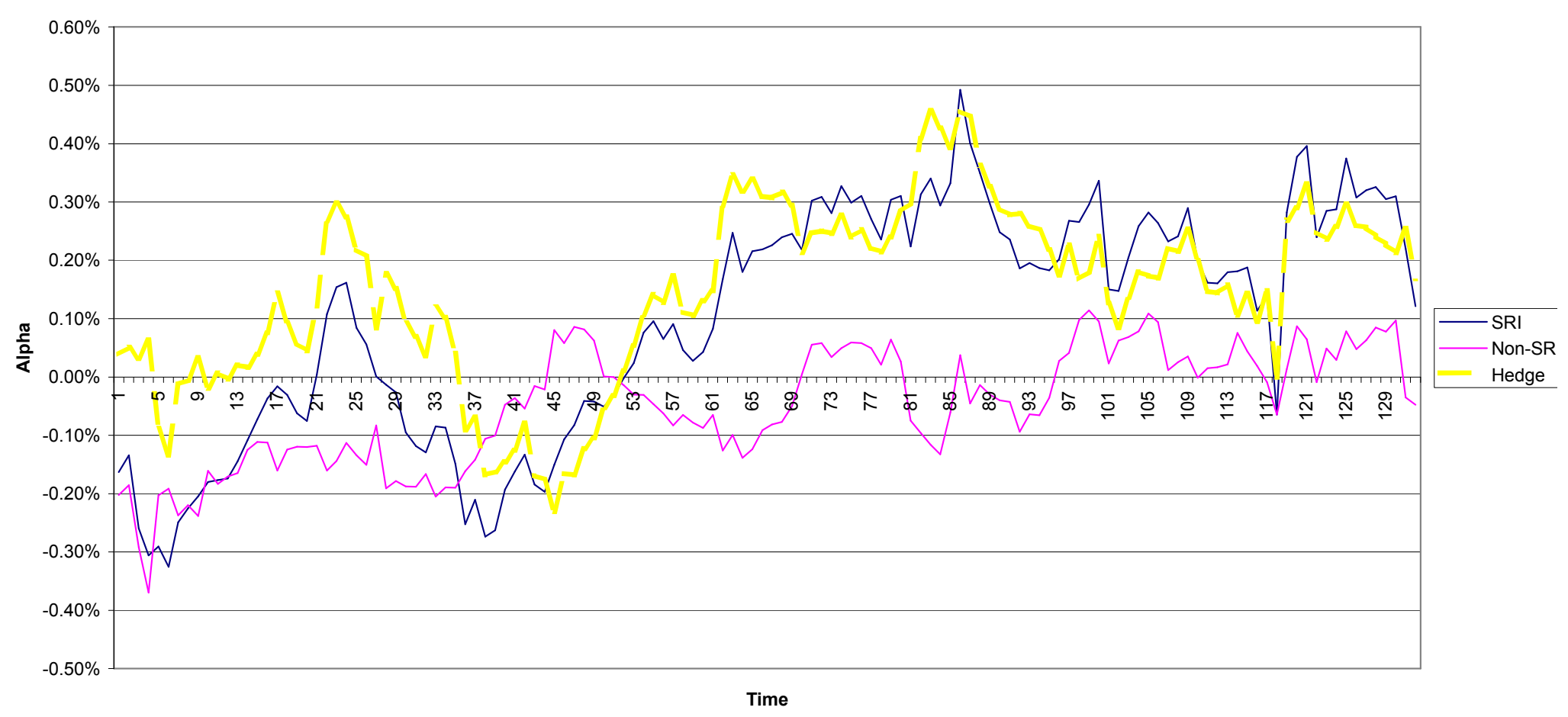

Figure 1: Rolling Calendar Time 4-factor Alphas, Domestic 
Calendar Time 4-Factor Alphas

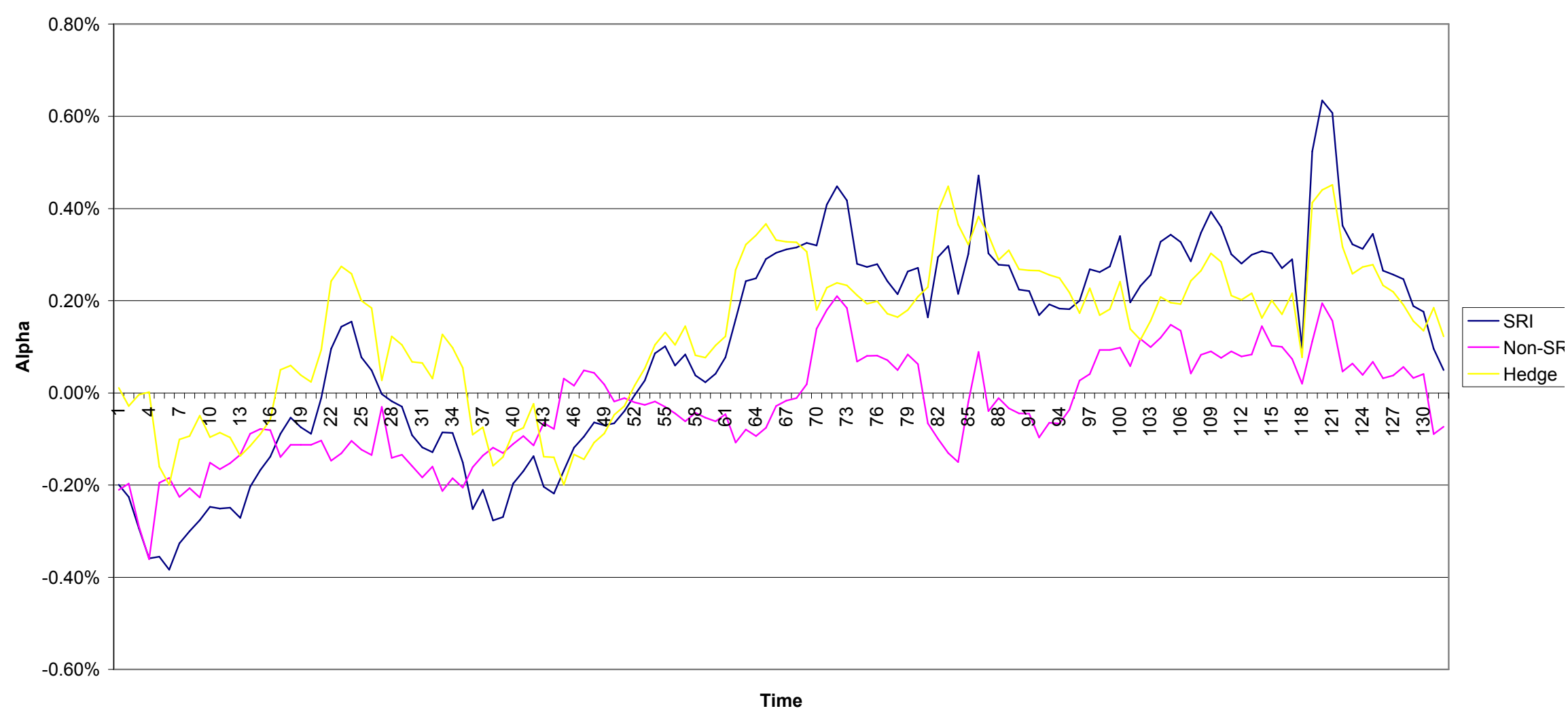

Figure 2: Rolling Calendar Time 4-factor Alphas, Domestic 
Calendar Time 3-Factor Alphas - International

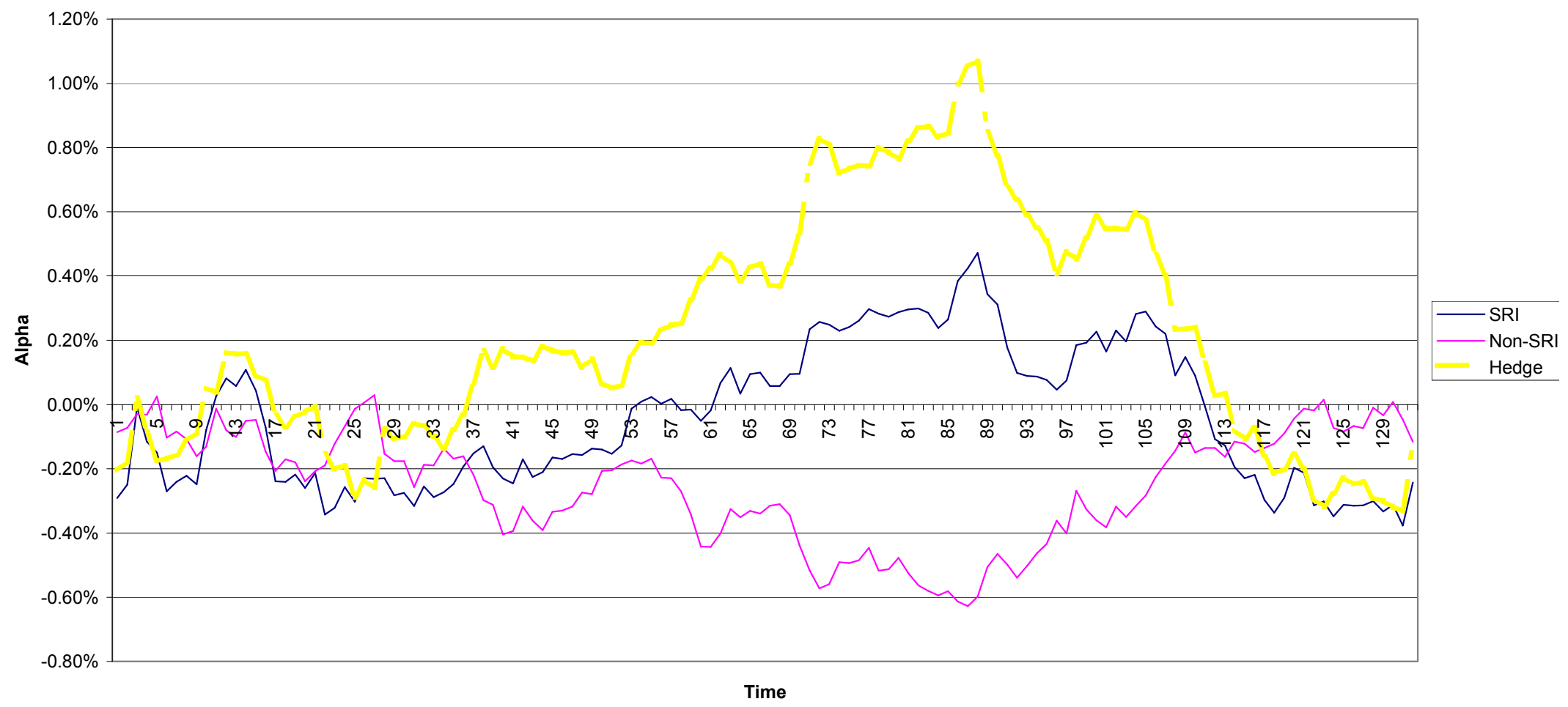

Figure 3: Rolling Calendar Time multi-factor Alphas, International 
Hedge portfolio coefficients - 3 factor Domestic

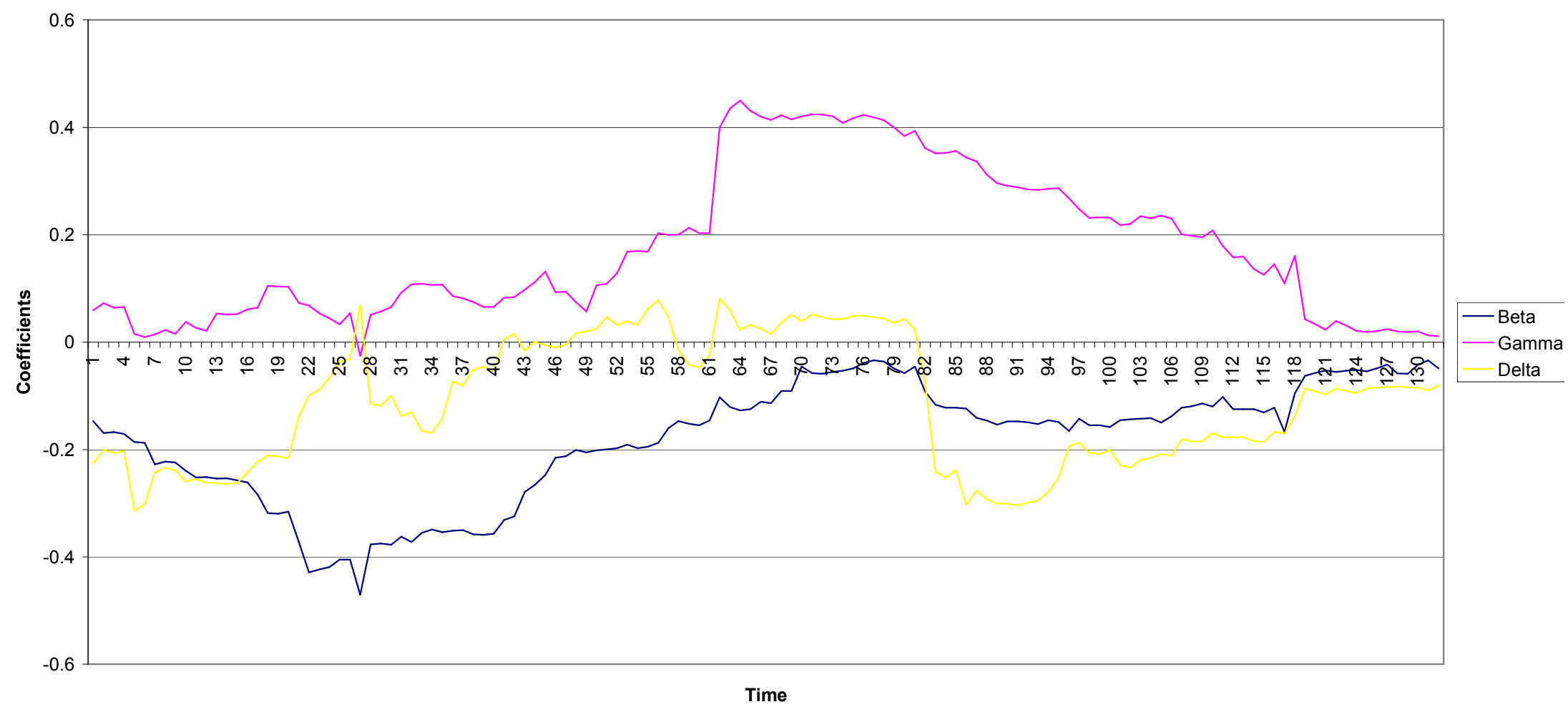

Figure 4: Rolling Calendar Time 3-factor Hedge Fund coefficients, Domestic 
Hedge portfolio coefficients

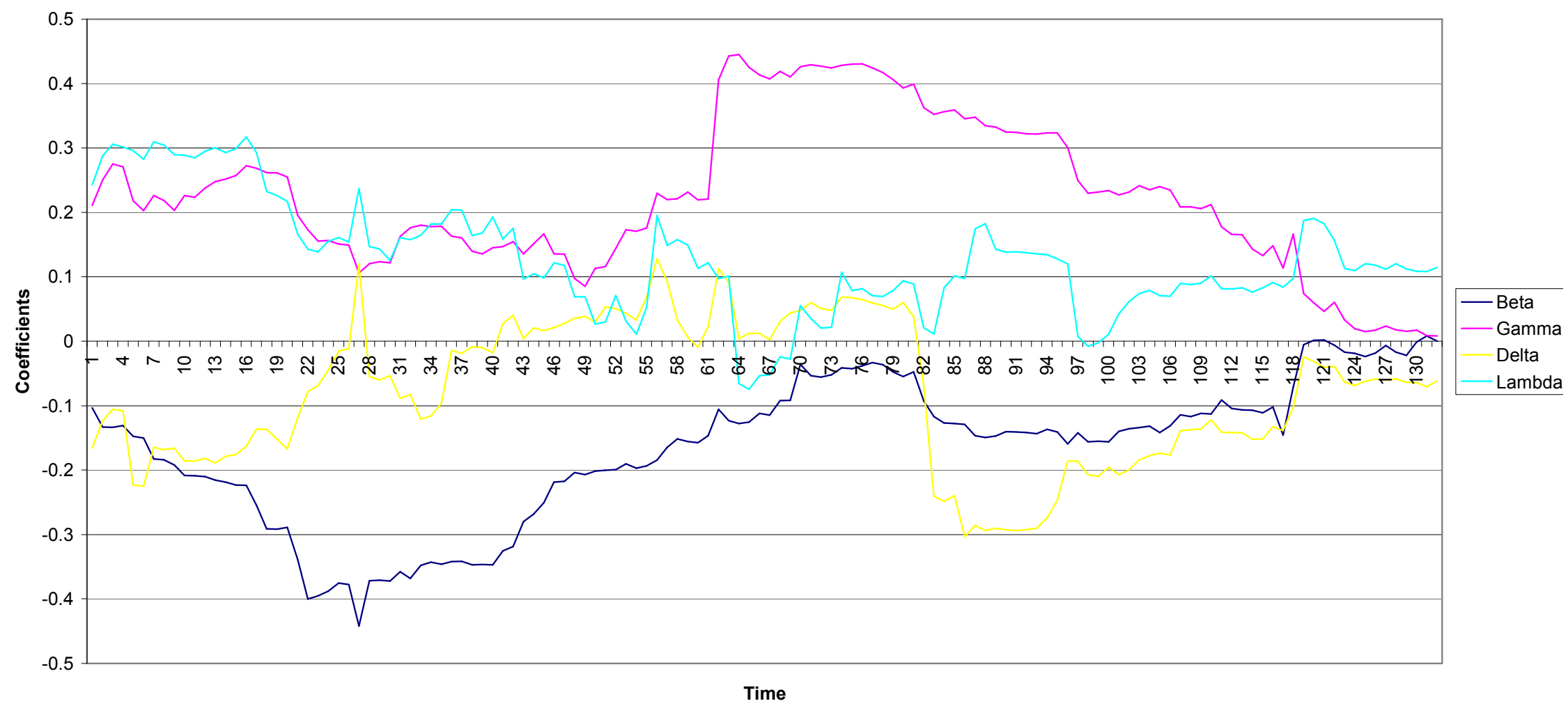

Figure 5: Rolling Calendar Time 4-factor Hedge Fund coefficients, Domestic 
Hedge portfolio coefficients - International

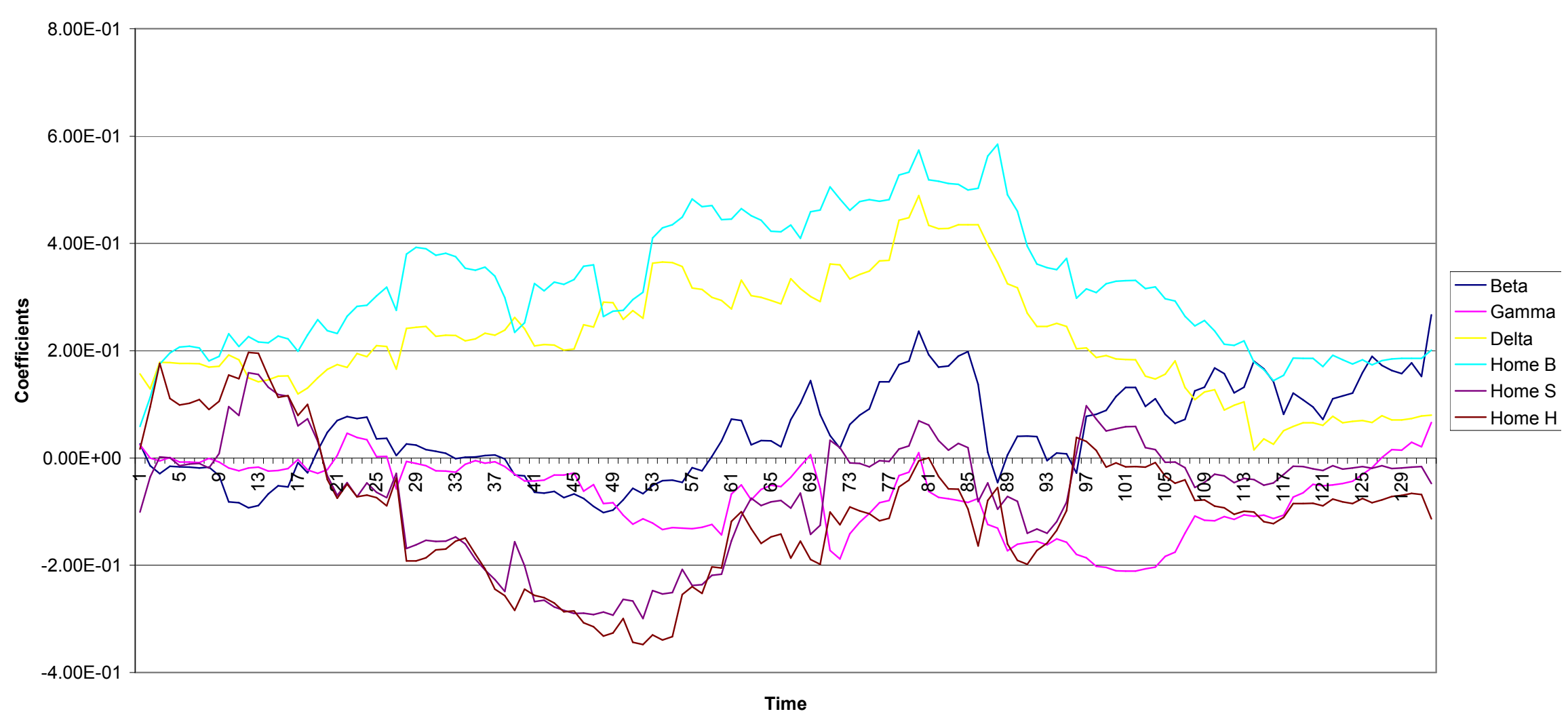

Figure 6: Rolling Calendar Time multi-factor Hedge Fund coefficients, Domestic 